\title{
The dynamic interplay between saline fluid flow and rock permeability in magmatic- hydrothermal systems
}

Journal Article

Author(s):

Weis, Philipp

Publication date:

2015-02

Permanent link:

https://doi.org/10.3929/ethz-b-000096623

Rights / license:

In Copyright - Non-Commercial Use Permitted

Originally published in:

Geofluids 15(S 1-2), https://doi.org/10.1111/gfl.12100 
This is the Green Open Access version of: Weiss, P., 2015. The dynamic interplay between saline fluid flow and rock permeability in magmatic-hydrothermal systems. Geofluids, vol.15, pp. 350-371.

Original publication see: https://doi.org/10.1111/gfl.12100

\title{
The dynamic interplay between saline fluid flow and rock permeability in magmatic-hydrothermal systems
}

\author{
Philipp Weis \\ Institute of Geochemistry and Petrology, ETH Zurich, Zürich, Switzerland
}

Key words: brittle-ductile transition, geothermal energy, hydraulic fracturing, magmatic-hydrothermal ore deposits, numerical modelling, permeability

\begin{abstract}
Magmatic-hydrothermal ore deposits document the interplay between saline fluid flow and rock permeability. Numerical simulations of multiphase flow of variably miscible, compressible $\mathrm{H}_{2} \mathrm{O}-\mathrm{NaCI}$ fluids in concert with a dynamic permeability model can reproduce characteristics of porphyry copper and epithermal gold systems. This dynamic permeability model uses values between $10^{-22}$ and $10^{-13} \mathrm{~m}^{2}$, incorporating depth-dependent permeability profiles characteristic for tectonically active crust as well as pressure- and temperature-dependent relationships describing hydraulic fracturing and the transition from brittle to ductile rock behavior. In response to focused expulsion of magmatic fluids from a crystallizing upper crustal magma chamber, the hydrothermal system self-organizes into a hydrological divide, separating an inner part dominated by ascending magmatic fluids under nearlithostatic pressures from a surrounding outer part dominated by convection of colder meteoric fluids under near-hydrostatic pressures. This hydrological divide also provides a mechanism to transport magmatic salt through the crust. With a volcano at the surface above the hydrothermal system, topography-driven flow reverses the direction of the meteoric convection as compared to a flat surface, leading to discharge at distances of up to $7 \mathrm{~km}$ from the volcanic center. The same physical processes at similar permeability ranges, crustal depths, and flow rates are relevant for a number of active systems, including geothermal resources and excess degassing at volcanos. The simulations further suggest that the described mechanism can separate the base of free convection in high-enthalpy geothermal systems from the magma chamber as a driving heat source by several kilometers in the
\end{abstract}


vertical direction in tectonic settings with hydrous magmatism. These root zones of high-enthalpy systems may serve as so-called super-critical geothermal resources. This hydrology would be in contrast to settings with anhydrous magmatism, where the base of the geothermal systems may be closer to the magma chamber.

\section{Introduction}

Fluids in the Earth's crust have a critical control on a large number of geological processes on widely varying temporal and spatial scales (cf. Ingebritsen \& Gleeson 2015). The presence of fluids may decide whether and how a physical or chemical process takes place, ranging from slow metamorphism in orogenic roots to catastrophic volcanic eruptions from hydrous magma chambers. Wherever fluids play a major role, observed or inferred processes exhibit a strong interplay between fluid and rock, often leading to episodic behavior or a tendency toward self-organization, such as fault-valve behavior in fractures, compaction-driven porosity waves or hydraulic fracturing (e.g., Sibson et al. 1988; Connolly \& Podladchikov 2004; Cox 2005; Preisig et al. 2015; Saffer 2015). In most cases, however, a quantitative and comprehensive understanding of how these processes act in natural systems is still in its infancy.

Magmatic-hydrothermal ore deposits are fossil witnesses of dynamic permeability creation and reduction in response to forced fluid flow (Hedenquist \& Lowenstern 1994; Cox 2005; Sillitoe 2010). Open pit and underground mining of mineral deposits provide valuable three-dimensional insights into several kilometers of the crust with outcrops, drill cores, and geochemical mapping. Cross-cutting relationships, alteration patterns, and fluid inclusions can document the temporal and spatial evolution of the hydro-thermal systems. The variety of different hydrothermal alteration overprints and vein sequences with different mineral assemblages may result from a unique, complex history of ore formation for any individual deposit. However, the classification of distinct deposit types with characteristic patterns and their global abundance in typical geological settings (Kesler 1994; Heinrich \& Candela 2014) suggest that their formation results from recurrent combinations of hydrological and geological processes, resulting from the interplay between fluid flow and rock permeability.

Due to its extent over several kilometers of the crust and its lifetime over multimillennia, the spatial and temporal evolution of magmatic-hydrothermal systems cannot be assessed with observation techniques alone. Therefore, mass- and energy-conserving numerical methods describing the interactions between fluid and rock provide a powerful tool for quantifying the key processes controlling these dynamic hydrothermal systems (e.g., Ingebritsen et al. 2010). In numerical 
simulations, permeability has traditionally been regarded as a static material property determining how fast ground water can flow through a porous rock formation according to Darcy's law (Ingebritsen et al. 2006). Extending the concept of this continuum, porous medium approach to the characterization of fluid flow through a fractured rock mass, however, requires a revised concept of permeability as a dynamic parameter.

This study presents results from numerical simulations of the hydrology of porphyry copper systems. The model includes multiphase flow of compressible, variably miscible $\mathrm{H}_{2} \mathrm{O}-\mathrm{NaCl}$ fluids with an accurate thermodynamic description of phase relations and fluid properties as well as a dynamic permeability model describing the transition from brittle to ductile rock behavior and hydraulic fracturing. Building on previous simulation results (Weis et al. 2012), the present study investigates the influence of permeability range, salinity, and volcano topography on the hydrology of porphyry systems and discusses its relation to active systems such as geothermal fields and volcanos.

\section{Porphyry copper and epithermal gold deposits}

Porphyry-type deposits form in continental collisional arcs within the upper crust and are characterized by typical sequences of intense veining and alteration due to ascending fluids (Gustafson \& Hunt 1975; Sillitoe 2010; Richards 2013; Wilkinson 2013). Geologic observations show that the deposits are closely associated with volcanic activity and that the veins form from magmatic fluids expelled from a large upper crustal magma chamber (Hedenquist \& Lowenstern 1994; Wilkinson 2013). Intense stockwork veining indicates that the host rock has been fractured and sealed in multiple cycles, which episodically created permeability to release the fluids expelled from the magma chamber. Cathodoluminescence images of copper-bearing quartz veins indicate that the early stages of vein formation are barren and that mineralization is associated with a generation of later quartz (Landtwing et al. 2005).

Some porphyry copper systems are inferred to be linked to epithermal gold deposits at shallower crustal levels (Henley \& Ellis 1983; Hedenquist et al. 1998; Sillitoe 2010; Richards 2013). At lowsulfidation epithermal deposits, layers of different mineral assemblages reflect the temporal evolution of the system and may document several cycles. Within the vein deposit, mineralization with metal concentrations of economic grade is usually restricted to thin layers, which are often associated with boiling of the ore-forming hydrothermal fluid (Izawa et al. 1990). 
Fluid inclusions trapped in vein minerals can document the state of the hydrothermal system before, during and after ore formation. Magmatic fluids expelled from the underlying cooling magma are injected into the host rock as high-temperature, high-pressure single-phase fluids with an intermediate density (around 500-600 $\mathrm{kgm}^{-3}$ ) and a salinity of about $10 \mathrm{wt} \% \mathrm{NaCl}$ (Redmond etal. 2004; Landtwing et al. 2005). Upon ascent toward the surface, this pristine fluid phase separates into a low-salinity, lowdensity vapor phase and a high-salinity, high-density brine phase. These fluid phases can physically separate from each other and flow with different phase velocities. Numerous fluid inclusion studies document brines and vapors with variable salinities and homogenization temperatures, often occurring as so-called boiling assemblages where a two-phase fluid mixture has been trapped within a single crack, which later becomes preserved as a trail of fluid inclusions (e.g., Redmond et al. 2004; Landtwing et al. 2005; Bodnar etal. 2014).

Copper mineralization in porphyry deposits is associated with a decrease in temperature of the fluids from initially $600-700^{\circ} \mathrm{C}$ to values between 350 and $450^{\circ} \mathrm{C}$ (Hezarkh-ani \& Williams-Jones 1998; Herzarkhani et al. 1999; Landtwing et al. 2005). Epithermal deposits are generally characterized by temperatures below $300^{\circ} \mathrm{C}$ (Bodnar et al. 2014). To ensure enrichment to economic grades over time, the physical hydrology has to provide a robust cooling and ore precipitation mechanism.

Numerical simulations of the hydrology of porphyry systems suggest that ore formation occurs at a selfsustaining hydrological divide related to the interplay of fluid flow and rock mechanics (Weis et al. 2012). The inner part of the magmatic fluid plume is dominated by hot magmatic fluids ascending under near-lithostatic fluid pressures. The ascending fluids heat the host rock above the inferred transition temperature from brittle to ductile (plastic, viscous) behavior of dry rock (Fournier 1999), leading to a permeability reduction. This effect is counteracted by the incoming fluids, because fluid pressure can cause transient embrittlement by bringing rock to failure and creating permeable pathways. As a result, magmatic fluids ascend in overpressure-permeability waves through this inner part (Weis et al. 2012). From the outside, this magmatic fluid plume is cooled by convection of meteoric fluids under nearhydrostatic fluid pressures. This hydrology stabilizes a sharp temperature-pressure front that matches with conditions for porphyry copper mineralization, while conditions favorable for epithermal deposits develop in shallower depths where the convecting meteoric water admixes in variable proportions with surges of magmatic fluids, inducing episodic boiling events.

The concept of a hydrological divide will be an essential part of the work discussed here. The term 'divide' is used to indicate a boundary between two domains in the system. The first is dominated by magmatic fluids, near-lithostatic pressures, high temperatures, ductile rock behavior, and low 
permeabilities. The second is dominated by meteoric fluids, near-hydrostatic pressures, lower temperatures, brittle rock behavior, and higher permeabilities. The divide is marked by a stable pressure-temperature front, which is controlled by the heat balance between the different flow regimes in the two domains. However, the dynamic flow behavior of ascending magmatic fluids causes the nominally ductile rock to temporarily become more permeable due to episodic embrittlement by hydraulic fracturing. These surges also result in magmatic fluids flowing across the hydrological divide, which leads to temporarily dynamic behavior at the otherwise stable pressure-temperature front. For better readability, the term ductile will occasionally be used to identify the transiently overpressured regime, even though it is characterized both by ductile and episodic brittle behavior.

\section{Method}

Fluid flow in magmatic-hydrothermal systems can be described with a continuum, porous medium approach according to Darcy's law. To quantify the interplay of saline fluid flow and rock permeability, the numerical model requires (i) the implementation of a thermodynamic model that can accurately describe the phase relations and fluid properties over the relevant ranges of temperature, pressure, and composition; (ii) the implementation of a dynamic permeability model that maps existing permeability-related models to the continuum approach; and (iii) a numerical method that can handle multiphase flow of compressible, variably miscible $\mathrm{H}_{2} \mathrm{O}-\mathrm{NaCl}$ fluids in the presence of large source terms that arise from fluid expulsion and phase separation.

\subsection{Multiphase flow of $\mathrm{H}_{2} \mathrm{O}-\mathrm{NaCl}$ fluids}

Subsurface fluid flow in porous and fractured media can be described with an extended form of Darcy's law with

$$
v_{i}=-k \frac{k_{r i}}{\mu_{i}}\left(\nabla p-\rho_{i} g\right) \quad i=\{v, l\},
$$

where $v_{i}$ is the Darcy velocity of the mobile phases $i$, which can be vapor $v$ and liquid $l$, the permeability $k$, the relative permeability $k_{r}$ of the phase indicated, the fluid viscosity $\mu$, the total fluid pressure $p$, the fluid density $\rho$, and the acceleration due to gravity $g$ (Ingebritsen et al. 2006). Saline fluids can also saturate in a solid halite phase $h$, which is assumed to reduce the available permeability for the mobile phases by applying a linear relative permeability model which ensures that

$$
k_{r v}+k_{r l}=1-S_{h},
$$

where $S$ is the volumetric saturation of the phase indicated, and a residual saturation of $R_{v}=0.0$ for the 
vapor and $R_{l}=0.3\left(1-S_{h}\right)$ for the liquid phase (Weis et al. 2014).

Conservation of fluid mass is calculated as

$$
\frac{\partial\left(\phi\left(S_{l} \rho_{l}+S_{v} \rho_{v}+S_{h} \rho_{h}\right)\right)}{\partial t}=-\nabla \cdot\left(v_{l} \rho_{l}\right)-\nabla \cdot\left(v_{v} \rho_{v}\right)+Q_{\mathrm{H}_{2} \mathrm{O}+\mathrm{NaCl}}
$$

with the porosity $\emptyset$, the time $t$, and a source term $Q_{\mathrm{H}_{2} \mathrm{O}+\mathrm{NaCl}}$. Conservation of salt mass is described by

$$
\frac{\partial\left(\phi\left(S_{l} \rho_{l} X_{l}+S_{v} \rho_{v} X_{v}+S_{h} \rho_{h} X_{h}\right)\right)}{\partial t}=-\nabla \cdot\left(v_{l} \rho_{l} X_{l}\right)-\nabla \cdot\left(v_{v} \rho_{v} X_{v}\right)+Q_{\mathrm{NaCl}},
$$

with $X$ being the mass fraction of $\mathrm{NaCl}$ and a source term $Q_{\mathrm{NaCl}}$. Conservation of energy is obtained by

$$
\frac{\partial\left[(1-\phi) \rho_{r} h_{r}+\phi\left(S_{l} \rho_{l} h_{l}+S_{v} \rho_{v} h_{v}+S_{h} \rho_{h} h_{h}\right)\right]}{\partial t}=\nabla \cdot(K \nabla T)-\nabla \cdot\left(v_{l} \rho_{l} h_{l}\right)-\nabla \cdot\left(v_{v} \rho_{v} h_{v}\right)+Q_{e}
$$

with the subscript $r$ indicating the rock, the specific enthalpy $h$ of the phase indicated, the thermal conductivity $K$, the temperature $T$, and a source term $Q_{e}$.

Phase relations and fluid properties are calculated by a thermodynamic model according to the IAPS84 equation of state (Haar et al. 1984) for pure $\mathrm{H}_{2} \mathrm{O}$ and the effect of adding $\mathrm{NaCl}$ is described by the model of Driesner \& Heinrich (2007) and Driesner (2007). Fluid and rock are assumed to be in local thermal equilibrium, which requires that the total enthalpy is distributed over the fluid and rock contained in a control volume and fluid properties are updated by the numerical method at every modeling time step (Weis et al. 2014).

\subsection{Dynamic permeability}

The calculation of fluid flow in a continuum approach with Darcy's law (Eq. 1) requires that permeability can be described with values for the bulk property $k$ that are representative for the elements of the computational mesh of the modeling domain (Weis et al. 2012). For modeling the hydrology of porphyry copper deposits, simulations with static, homogeneous permeabilities were unable to reproduce a hydrothermal system that could explain all geological observations. Only after assembling a dynamic permeability model by mapping existing models for permeability, stress state, and failure conditions of the continental upper crust, a hydrothermal system with a steady, selfsustaining enrichment mechanism in agreement with observations developed (Weis et al. 2012). This permeability model uses five general assumptions:

1. Permeability generally follows a depth-dependent profile characteristic for a tectonically active 
crust (Manning \& Ingebritsen 1999).

2. For the brittle crust, this profile is related to a nearly critically stressed crust (Zoback et al. 2002), resulting in a failure criterion for fractures at near-hydrostatic fluid pressure conditions (Cox 2010).

3. With increasingly ductile behavior of the rock due to heating, permeability decreases and differential stress relaxes at elevated temperatures (Fournier 1999), leading to failure criteria at near-lithostatic fluid pressures (Cox 2010). Depending on rock type and strain rate, this brittle-ductile transition may start at a temperature of $360^{\circ} \mathrm{C}$ (Hayba \& Ingebritsen 1997).

4. Elevated fluid pressures can counteract the effect of temperature-dependent permeability closure, ensuring that permeability has the value of its characteristic profile when fluid pressures reach the failure criterion (Manning \& Ingebritsen 1999; Cox 2005, 2010; Ingebritsen \& Manning 2010).

5. Hydraulic fracturing temporarily and locally increases permeability by up to two orders of magnitude higher than the characteristic permeability profile (Ingebritsen \& Manning 2010), whenever fluid pressures exceed the respective stress state-dependent failure criterion.

Permeability ranges are generally limited to a maximum of $10^{-14} \mathrm{~m}^{2}$, which is the reference permeability at $1 \mathrm{~km}$ depth in the study of Manning \& Ingebritsen (1999). Sensitivity studies use permeabilities of up to $10^{-13} \mathrm{~m}^{2}$.

\subsubsection{Background permeability}

Compilations of permeability estimates representative for tectonically active continental crust follow a characteristic, depth-dependent profile, which can be described as

$$
\log k=-14-3.2 \log z
$$

with the permeability $k$ in $\mathrm{m}^{2}$ and the depth $z$ in $\mathrm{km}$ (Manning \& Ingebritsen 1999). This profile is interpreted to represent time averages and the dynamic permeability model presented here uses this relation as background values for permeability evolution (Fig. 1A). At brittle conditions, these values are maintained as long as fluid pressures are below or equal to the failure criterion. With the beginning of ductile behavior, the values are used as reference permeability for the case when fluid pressure equals the failure criterion (Fig. 2A). In simulations with a volcano topography, the depth-dependent permeability is calculated in relation to the level of the flat surface at the foot of the volcano, while the volcano is assigned the maximum permeability of $10^{-14} \mathrm{~m}^{2}$ (or $10^{-13} \mathrm{~m}^{2}$ for sensitivity studies). 

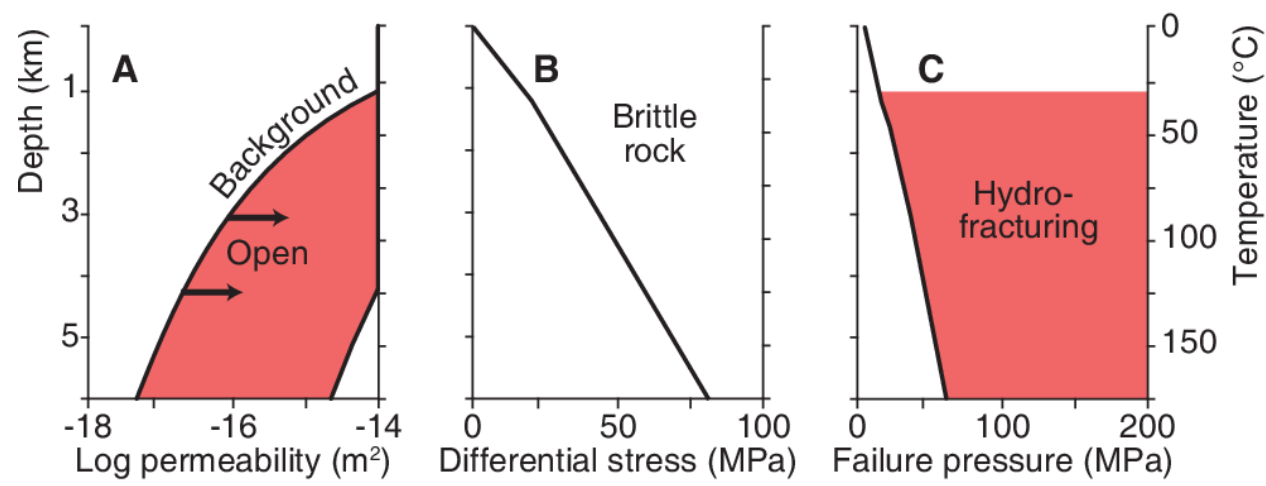

Figure 1. Dynamic permeability model for the brittle crust at temperatures imposed by a normal geothermal gradient. A: Depth-dependent permeability profile for average (background; lower limit of light gray area) and perturbed (light gray area) continental crust. B: Stress state of the crust at near-critical conditions. C: Hydrofracturing (light gray area) is described by incrementally increasing permeability for fluid pressures above a stress state-dependent failure criterion. The light gray area marks the field of fluid pressures that are not sustainable, because they exceed the pressure at failure.

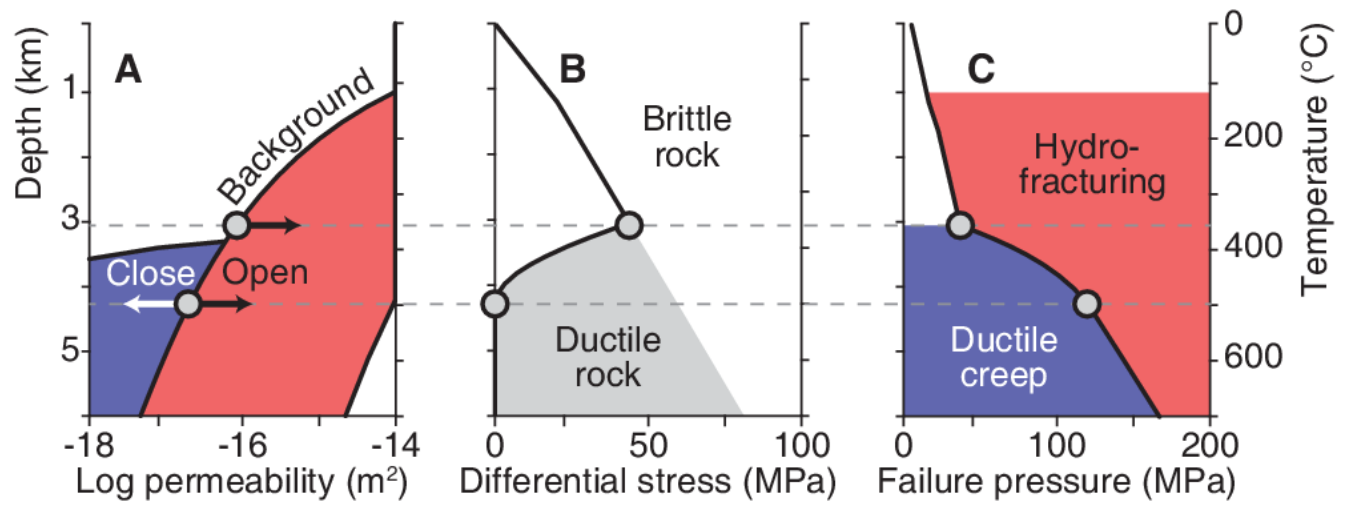

Figure 2. Transition from brittle to ductile rock behavior within the dynamic permeability model at elevated temperatures imposed by a magmatic heat source. The gray dashes mark the inferred temperature interval for the brittle-ductile transition $\left(360\right.$ to $\left.500^{\circ} \mathrm{C}\right)$. The linear temperature profile with depth schematically illustrates the constitutive relationships. A: Permeability profile as in Fig. $1 \mathrm{~A}$ with superimposed permeability closure athigh temperatures (dark gray area; Fig. 3A). B: Differential stress (Fig. 1B) relaxes with elevated temperatures. C: The failure criterion at nominally ductile conditions increases to values at near-lithostatic pressure conditions. Fluid pressure-depend ent permeability counteracts the temperature-dependent permeability closure at conditions of ductile creep (dark gray area; Fig. 3B). After Weis et al. (2012).

\subsubsection{Critically stressed brittle crust}

Measurements from the KTB scientific research borehole show that differential stress increases with depth and can have values close to hydrostatic fluid pressures for the uppermost $10 \mathrm{~km}$ at temperatures following a normal geothermal gradient (Zoback \& Harjes 1997; Zoback et al. 2002). For brittle conditions, the dynamic permeability model assumes a constant, homogeneous near-critical stress state of the crust under normal-faulting conditions (Fig. 1B). The maximum principal stress $\sigma_{1}$ is equal to the vertical stress $\sigma_{v}$. As a simplification, the vertical stress is calculated as being equal to the rock overburden given by the lithostatic pressure gradient. Differential stress given by $\sigma_{\text {diff }}=\sigma_{1}-\sigma_{3}$ (with the minimum principal stress $\sigma_{3}$ ) is assumed to be $5 \mathrm{MPa}$ above the initial hydrostatic pressure. 
The failure criterion for brittle shear expressed with the pore fluid factor

$$
\lambda_{v}=\frac{p_{\text {fluid }}}{\sigma_{v}}
$$

is given by the relation

$$
\lambda_{v}=\frac{\left(4 C-\sigma_{1}+4 \sigma_{3}\right)}{3 \sigma_{v}}
$$

where $C$ is the cohesive strength of the rock (Eq. 8 in Cox 2010). Rearranging the equation gives the fluid pressure at failure ( $p_{\text {fluid }}=p_{\text {fail }}$ ) for brittle shear at normal-faulting conditions with

$$
p_{\text {fail }}=\sigma_{v}-\frac{4\left(\sigma_{\text {diff }}-C\right)}{3}
$$

Extension failure is given by the relation

$$
\lambda_{v}=\frac{\sigma_{3}+T}{\sigma_{v}},
$$

with the tensile strength of the rock T (Eq. 12 in Cox 2010). Rearranging this equation leads to a failure pressure of

$$
p_{\text {fail }}=\sigma_{v}-\sigma_{\text {diff }}+T \text {. }
$$

Assuming a cohesive strength of $10 \mathrm{MPa}$ and a tensile strength of $5 \mathrm{MPa}$, the two curves intersect at $\sigma_{\text {diff }}=5 T=2.5 C$. Above this value, the failure criterion of brittle shear is reached first, while extension failure happens below this threshold (Fig. 1C).

The dynamic permeability model used for this study calculates this stress field once at the beginning of the simulation from the initial conditions. During the simulation, the stress field and its variations are not explicitly evaluated for the domain, except for a temperature-dependent relation describing the transition from brittle to ductile behavior of the rock.

\subsubsection{Brittle-ductile transition}

With a temperature profile of a regular geothermal gradient (as in Fig. 1), the brittle-ductile transition is located at about $10 \mathrm{~km}$ depth. At deeper crustal levels, the stress state gradually relaxes (Zoback et al. 2002). This ductile region is related to low permeabilities where conductive heat transfer dominates over advective heat transport (Hayba \& Ingebritsen 1997; Ingebritsen et al. 2006). The presence of upper crustal magmatism can locally move this brittle-ductile transition to shallower depths (Fig. 2) 
around the magmatic intrusion and can be approximated in dependence on rock properties, temperature, and strain rate (Fournier 1999).

The dynamic permeability model used for this study adopts the temperature-dependent permeability approach of Hayba \& Ingebritsen (1997), where $k$ is assumed to decrease log-linearly with temperatures above $360^{\circ} \mathrm{C}$ to essentially impermeable values $\left(k=10^{-22} \mathrm{~m}^{2}\right)$ at $500^{\circ} \mathrm{C}(\mathrm{Fig}$. $2 \mathrm{~A})$. In this study, temperature-dependent permeability is calculated in relation to a reference value of $10^{-14} \mathrm{~m}^{2}$ (or $10^{-13} \mathrm{~m}^{2}$ for sensitivity studies) and starts to dominate as soon as the temperature-dependent value is lower than the depth-dependent permeability (Fig. 3A).
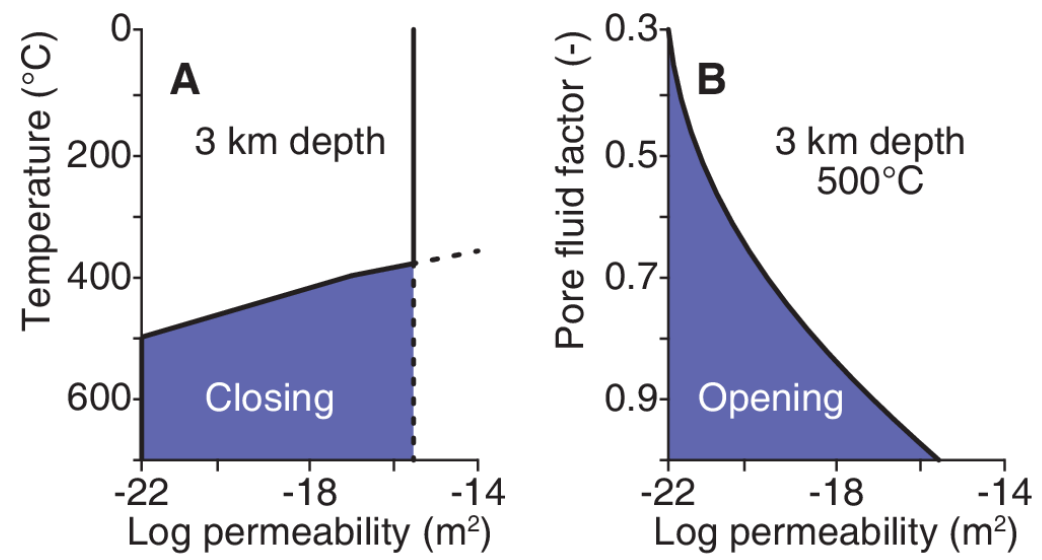

Figure 3. Constitutive relationships for permeability at ductile conditions. A: Permeability closes with elevated temperatures. B: Permeability closure is counteracted by elevated fluid pressures; Pore fluid factor is fluid pressure divided by failure pressure (see Fig. 2C). After Weis et al. (2012).

The transition from brittle to ductile behavior of the rock also leads to a decrease in differential stress within the same temperature interval as the temperature-dependent permeability (Fig. 2B). The local stress state-dependent failure criterion is then recalculated according to Eqs 9 or 11 (Fig. 2C). At temperatures above $500^{\circ} \mathrm{C}$, this relationship leads to $\sigma_{\text {diff }}=0$, which results in a failure pressure above lithostatic with

$$
p_{\text {fail }}=\sigma_{v}+T \text {. }
$$

With higher strain rates, the temperature interval of the brittle-ductile transition may move to higher values (Fournier 1999). For simulations of this study, however, we keep the strain rate constant. The assumption $\sigma_{\text {diff }}=0$ implies that all stresses are uniform and equal to the rock overburden, which is a further simplification. Repeated brittle shear failure may also lead to a progressive reduction in differential stress (Cox 2010) but is neglected here because it would not be straightforward to quantify 
and parameterize.

\subsubsection{Pressure-dependentpermeability}

The temperature-dependent decrease in permeability is assumed to be counteracted by an elastic opening of permeable structures where elevated fluid pressures work against the loss of interconnected pore space (Fig. 2C). If temperature-dependent permeability dominates over the depthdependent value and tends to decrease permeability, permeability is increased with fluid pressures above hydrostatic in dependence on a modified pore fluid factor $\lambda$ in relation to the failure pressure instead of the lithostatic pressure,

$$
\lambda=\frac{p_{\text {fluid }}}{p_{\text {fail }}}
$$

in a log-quadratic way (Fig. 3B). This parameterization mimics results from permeability experiments (Cox 2005) and is similar to other constitutive relationships for fluid pressure-dependent permeabilities (Rice1992).

\subsubsection{Hydraulicfracturing}

Compilations of transient permeability-creating events suggest that permeability can temporarily be increased by two to three orders of magnitude higher than the characteristic profile used as a background curve (Ingebritsen \& Manning 2010). Whenever fluid pressure exceeds the stress statedependent failure pressure determined by Eqs 9,11 or 12 ( $p_{\text {fluid }}>p_{\text {fail }}$ ) permeability is incrementally increased until fluid overpressure is released ( $p_{\text {fluid }}>p_{\text {fail }}$ ). For the sake of consistency between the different components of the dynamic permeability model, the $\lambda^{2}$-dependence is inherited (see Eq. 13) to incrementally increase permeability with

$$
\frac{k_{t+\Delta t}}{k_{t}}=\lambda^{2}=\left(\frac{p_{\text {fluid }}}{p_{\text {fail }}}\right)^{2},
$$

where the subscript $t$ indicates the current time level and $t+\Delta t$ denotes the following modeling time step. Permeabilities are limited to values exceeding the background profile by two orders of magnitude or the maximum permeability (Figs $1 \mathrm{~A}$ and $2 \mathrm{~A}$ ). After release of the overpressure, permeability is immediately reduced to the background value. This parameterization of hydraulic fracturing accounts for field observations documenting that rocks are fractured and sealed by vein formation in multiple cycles. The relation further allows to use a uniform mechanism for permeability creation independent of whether it occurs at near-hydrostatic or near-lithostatic fluid pressures. 
Other numerical simulations use different approaches for permeability creation and reduction. For (near-)lithostatic failure criteria, fluid pressure can be fixed at the values of failure and Darcy's law is solved for permeability instead of pressure (Hanson 1995). However, for (near-)hydrostatic failure criteria, this relationship can lead to unfavorable constellations where unreasonably drastic permeability changes are calculated because the driving force of Darcy's law, $\nabla p-\rho g$, is close or equal to zero. Other approaches scale permeability in dependence on effectivenormal stress, that is, on fluid pressure and stress state (Rice 1992; Miller et al.2004), which is also the foundation of the calculation of failure pressure in this study. However, these formulations are not designed for fluid pressures exceeding lithostatic pressure and will not necessarily lead to a reduction in fluid pressure below failure pressure as long as the fluid supply rate can maintain a fluid pressure gradient that is larger than the lithostatic pressure gradient.

The reduction to fluid pressures below the failure criterion can be assured by defining a dependency of permeability change on overpressure as given by Eq. 14 rather than a permeability-pressure relation. This approach requires more ad hoc parameterizations and aims at mimicking the effect of hydraulic fracturing as a response to forced fluid flow rather than at resolving the actual process of rock mechanics (cf. Rojstaczer et al. 2008).

\subsection{Control volume finite element method}

The numerical model used for this study is an implementation of the Complex Systems Modeling Platform (CSMP++, Matthai et al. 2007) for thermohaline convection, and the governing equations are solved with a control volume finite element method as described in detail by Weis et al. (2014). The method enables the use of unstructured meshes with varying resolution, which allows for mesh refinement in the most important parts of the domain. The approach further ensures that sharp solute and thermal fronts in advection-dominated flow systems as well as the physical separation of fluid phases can be resolved by using all fluid properties as calculated by the thermodynamic model and avoiding interpolations or averaging.

Fluid properties are defined as nodal values at the center of a respective control volume, while permeability is an elemental property. As finite elements include several nodes at their corners, the constitutive relationships of the dynamic permeability model are averaged, interpolated or accumulated. Depth-dependent permeability is calculated in reference to the vertical coordinate of the 
element's barycenter. For the calculation of temperature-dependent permeability values, first the respective nodal permeability is evaluated and then averaged to the element variable. The same holds for the counteracting fluid pressure-dependence for fluid pressures below the failure criterion. For the calculation of hydraulic fracturing, the effects of permeability change according to Eq. 14 are added up to ensure that elements where all corner nodes experience overpressure are more intensely fractured than elements where only one corner node is overpressured.

\subsection{Model configuration}

The modeling domain represents a two-dimensional section of the upper continental crust with a magma chamber of initially $900^{\circ} \mathrm{C}$ emplaced at $5 \mathrm{~km}$ depth (Fig. 4). The host rock porosity is kept constant with 0.05 , and the pore space is initially saturated with pure water under hydrostatic pressure and a thermal gradient of $22.5^{\circ} \mathrm{C} \mathrm{km}^{-1}$, which is maintained by a bottom heat flux of $45 \mathrm{~mW} \mathrm{~m}^{-2}$, and $10^{\circ} \mathrm{C}$ at the top boundary, representing the Earth's surface. During the simulation, the top boundary is open to any fluid outflow at atmospheric pressure and inflow of salt-free liquid water of $10^{\circ} \mathrm{C}$. The left, right, and bottom boundaries are no-flow boundaries. Rock properties are kept constant with a density of $2700 \mathrm{~kg} \mathrm{~m}^{-3}$, a thermal conductivity of $2 \mathrm{~W} \mathrm{~m}^{-1}{ }^{\circ} \mathrm{C}^{-1}$ and a heat capacity of $880 \mathrm{~J} \mathrm{~kg}^{-1}{ }^{\circ} \mathrm{C}^{-1}$. The magma chamber uses the same values but starts with a doubled heat capacity, which is gradually reduced with cooling of the magma chamber to account for the release of latent heat during crystallization (cf. Hayba \& Ingebritsen 1997).

\subsection{Expulsion of magmatic fluids}

The release rate of magmatic fluids to the host rock is calculated as being proportional to the crystallization rate of the magma chamber. At every modeling time step, the volume of the magma chamber that has cooled below an inferred solidus temperature of $700^{\circ} \mathrm{C}$ is evaluated. All elements that have one node below this solidus and one above it add to the total fluid production and the newly crystallized area within one two-dimensional element during the last time step is calculated as $A_{x}(t)$ (Fig. 5). If all nodes eventually cooled below the solidus temperature, the contributions $A_{x}(t)$ distributed over the modeling time steps have added up to the total area of the respective element and are subsequently considered to be part of the host rock. To also account for fluid accumulation in the third dimension, the magma chamber is inferred to have an elongated shape with half the width in the dimension perpendicular to the modeling section (Fig. 6). 

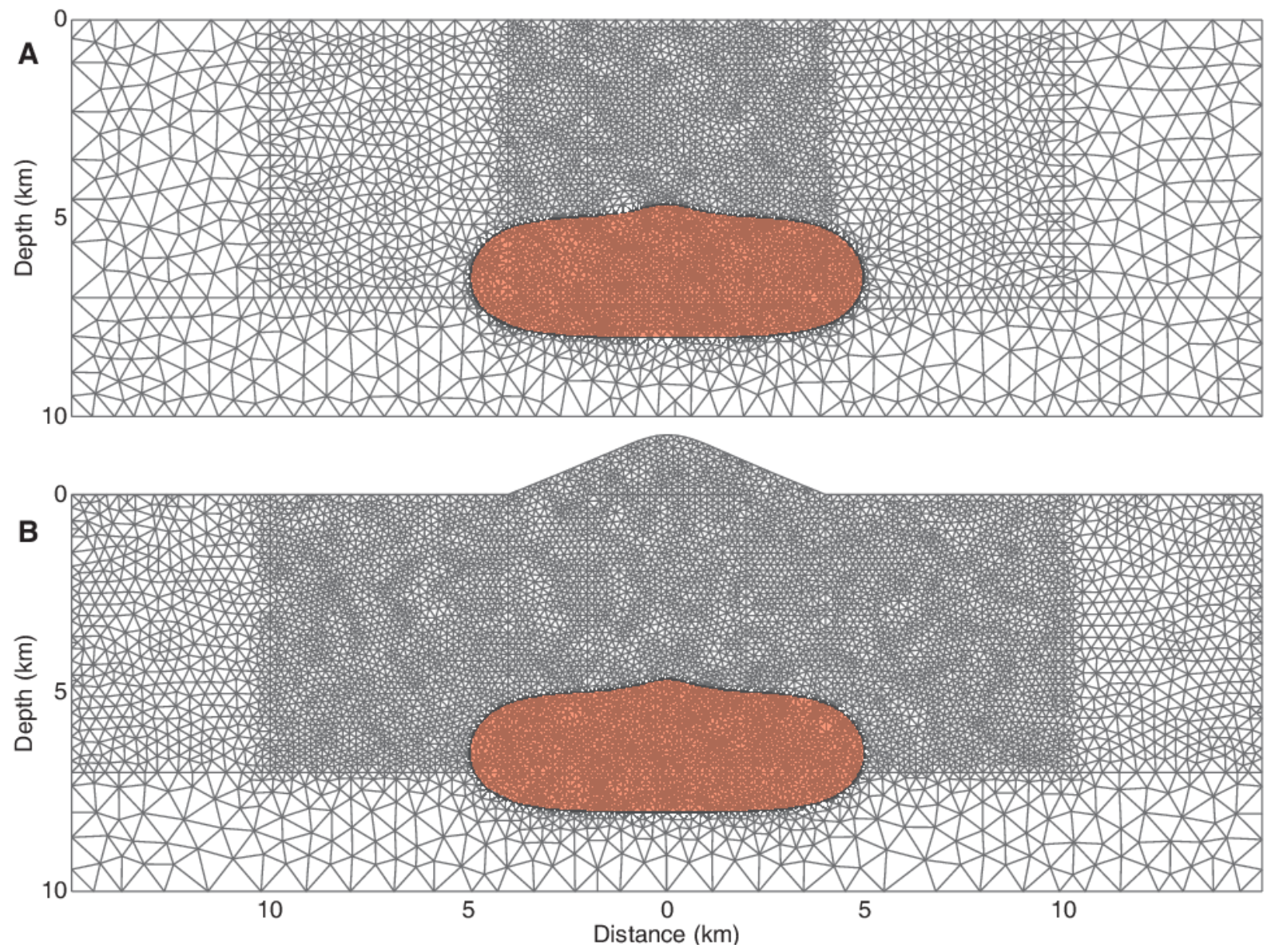

Figure 4. Model geometry and unstructured mesh with an elliptic magma chamber of about $3 \mathrm{~km}$ height and $10 \mathrm{~km}$ width and a cupola in the roof at $5 \mathrm{~km}$ depth with flat topography (A) and a central volcano of about $1.5 \mathrm{~km}$ height (B). The dimensions are taken from field observations of the Yerington Batholith (Dilles 1987).

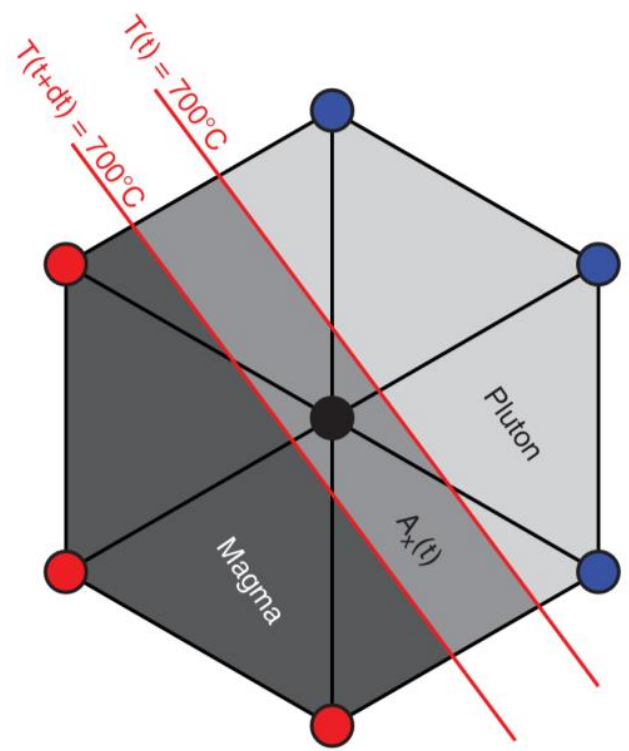

Figure 5. Crystallization of the magma chamber. The dark gray points indicate nodes of the modeling mesh with temperatures above the solidus temperature of $700^{\circ} \mathrm{C}$ and are considered to be part of the magma. The light gray nodes have already cooled below $700^{\circ} \mathrm{C}$ and are considered to be part of the solidified pluton. The black dot shows a node that cooled below the solidus temperature within one modeling time step $\mathrm{dt}$ as indicated by the $700^{\circ} \mathrm{C}$-isotherms at time $t$ and $t+\mathrm{d} t$. The newly crystallized area $A_{x}(t)$ at the magma-pluton interface is calculated as the area of the respective element lying between these two isotherms. 


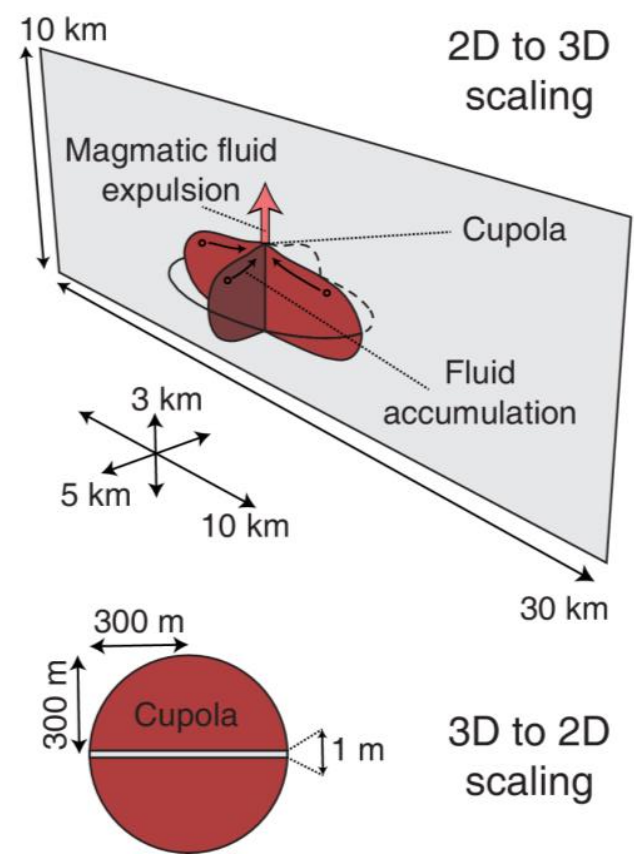

Figure 6. Fluid accumulation from a three-dimensional magma chamber. Fluids accumulate at the highest point underneath the roof of the magma chamber, which is approximated as a horizontal, circular cupola. The total amount of fluids released from a three-dimensional magma chamber is scaled back to the one-dimensional outline of the cup ola in the two-dimensional domain with a nominal thickness of $1 \mathrm{~m}$.

The total volume of newly crystallized magma is calculated as

$$
V_{\text {cryst }}(t)=\sum_{\text {elements }} f_{3 D} \cdot A_{x}(t),
$$

with a 2D-to-3D scaling factor

$$
f_{3 D}=\pi \cdot d x \cdot w_{y}
$$

where $\mathrm{d} x$ is the horizontal distance from the vertical center axis of the magma chamber to the barycenter of the element and $w_{y}$ is the aspect ratio of the horizontal dimensions of the magma chamber, that is, $w_{y}=0.5$ for the elongated shape of the magma chamber (Fig. 6). For an aspect ratio of $w_{y}=1.0$, the scaling factorgives the exact mathematical solution of the volume of an element rotating around an axis in a circle. As the calculation for the volume along an elliptical curve with a distorted element is not trivial, the simple scaling for $w_{y} \neq 1.0$ in Eq. 16 rather reflects a best estimate for the 3D volume.

Assuming a water content of $5 \%\left(C_{\text {water }}=0.05\right)$ of the rhyolitic melt that cannot be incorporated in the solidified igneous rock and is therefore released as a fluid phase, gives the total mass of magmatic fluid exsolved from this newly crystallized volume as

$$
m_{\text {fluid }}(t)=C_{\text {water }} \cdot \rho_{\text {rock }} \cdot V_{\text {cryst }}(t) \text {, }
$$

with the density of the rock $\rho_{\text {rock. }}$ This fluid mass is assumed to be expelled to the host rock through a 
cupola in the roof of the magma chamber during the following modeling time step. Assuming a circular, horizontal cross-section of this cupola with a radius of $R_{\text {cupola }}=300 \mathrm{~m}$ and a uniform distribution of the expelled fluid mass across the cupola, the total amount of fluid scaled back to the two-dimensional modeling domain can be calculated as

$$
m_{\text {source }}(t)=f_{2 D} \cdot m_{\text {fluid }}(t)
$$

with a 3D-to-2D scaling factor

$$
f_{2 D}=\frac{2}{\pi \cdot R_{\text {cupola }}} .
$$

The source term $m_{\text {source }}(t)$ is then evenly distributed across the nodes that represent the current location of the cupola and enter the system of conservation equations with the source term $Q_{\mathrm{H}_{2} \mathrm{O}+\mathrm{NaCl}}$ in Eq. 3. Assuming a salinity of $10 \mathrm{wt} \% \mathrm{NaCl}$ for the magmatic fluids results in a source term of $Q_{\mathrm{NaCl}}=0.1 \cdot Q_{\mathrm{H}_{2} \mathrm{O}+\mathrm{NaCl}}$ in Eq. 4. The thermodynamic model for $\mathrm{H}_{2} \mathrm{O}-\mathrm{NaCl}$ fluids then calculates the specific enthalpy $h_{\mathrm{H}_{2} \mathrm{O}+\mathrm{NaCl}}$ of a fluid of $700^{\circ} \mathrm{C}, 10 \mathrm{wt} \% \mathrm{NaCl}$ and the current fluid pressure at the injection node, resulting in a source of $Q_{e}=Q_{\mathrm{H}_{2} \mathrm{O}+\mathrm{NaCl}} \cdot h_{\mathrm{H}_{2} \mathrm{O}+\mathrm{NaCl}}$ in Eq. 5. The location of the cupola can retreat to greater depth following the isotherms of the solidus temperature.

\subsection{Proxies for vein formation and copper precipitation}

The formation of vein quartz is estimated by translating the accumulated permeability increases $\Delta k$ induced by hydraulic fracturing, and assuming a simple cubic law relationship (Walder \& Nur 1984) to a virtual void space $\Delta \phi$, assuming

$$
\frac{k_{0}+\Delta k}{k_{0}}=\left(\frac{\phi_{0}+\Delta \phi}{\phi_{0}}\right)^{3},
$$

where $k_{0}$ is the background permeability (Fig. 1A) and $\phi_{0}$ is the model's porosity $\phi$, which is kept constant during the simulations. The vein volume potential calculates the volume of quartz which could have precipitated if all the virtual open space would have been filled during vein sealing as

$$
\psi_{\text {veins }}=\frac{\Delta \phi}{1+\Delta \phi} \cdot 100
$$

and therefore represents an upper limit estimate (in \%) for vein density. The spatial and temporal distribution pattern of this proxy for vein density can be compared to field observations from porphyry 
copper deposits.

Copper is introduced as a tracer to the system of equations as

$$
\frac{\partial\left(\phi\left(S_{l} \rho_{l}+S_{v} \rho_{v}+S_{h} \rho_{h}\right) C_{C u}\right)}{\partial t}=-\nabla \cdot\left(v_{l} \rho_{l} C_{C u}\right)-\nabla \cdot\left(v_{v} \rho_{v} C_{C u}\right)+Q_{C u},
$$

with the copper concentration in the fluid $C_{\mathrm{Cu}}$ and a source term $Q_{\mathrm{Cu}}=C_{\mathrm{Cu}}^{\mathrm{initial}} \cdot Q_{\mathrm{H} 2 \mathrm{O}+\mathrm{NaCl}}$, reflecting a

copper concentration of $C_{\mathrm{Cu}}^{\text {initial }}=500 \mathrm{ppm}$ in the pristine fluid ex-solved from the magma chamber. Before precipitation, copper is advected as a passive tracer with the fluids and has no preferential fractionation behavior into the vapor, liquid, or halite phase. In reality, fractionation behavior may depend on whether $\mathrm{Cu}$ is preferentially forming complexes with CI or S (Pokrovski etal. 2008).

Experimental and fluid inclusion studies suggest that copper in porphyry copper systems is precipitated upon cooling of the copper-bearing fluid within the temperature interval between 450 and $350^{\circ} \mathrm{C}$ (Herzarkhani et al. 1999; Landtwing et al. 2005). Copper precipitation is therefore calculated as a function of temperature change. The copper enrichment potential within a control volume of the modeling mesh is calculated as

$$
\psi_{\mathrm{Cu}}=\frac{m_{\mathrm{Cu}}}{C_{\mathrm{Cu}}^{\text {initial }} \cdot C_{\text {water }} \cdot \rho_{\text {rock }} \cdot V},
$$

with the mass of precipitated copper $m_{c u}$ and the control volume $V$, which can be used for a rough estimate of the potential ore grade (in $\mathrm{wt} \%$ ) as

$$
G_{\mathrm{Cu}}=\frac{m_{\mathrm{Cu}}}{m_{\text {rock }}+m_{\mathrm{Cu}}} \cdot 100=\frac{\psi_{\mathrm{Cu}} \cdot C_{\mathrm{Cu}}^{\text {initial }} \cdot C_{\text {volatile }}}{1+\psi_{\mathrm{Cu}} \cdot C_{\mathrm{Cu}}^{\text {initial }} \cdot C_{\text {volatile }}} \cdot 100
$$

with the mass of the rock $m_{\text {rock }}$. The proxy for the formation of copper ore represents an upper limit estimate, as copper precipitation may be less efficient in nature. Furthermore, this estimate neglects sulfur availability, chemical equilibrium constants and chemical potential gradients that will affect the precipitation efficiency.

\section{Results}

The magma chamber conductively heats the surrounding host rock and induces convection of ambient fluids. As soon as heat conduction and advection have cooled the outer rim of the magma chamber below the solidus temperature, magmatic fluids are injected at the cupola and rapidly flow upward (Fig. 7A). The source rate of magmatic fluid injection in these early phases of the simulation is highest 
because the outermost layer of the three-dimensional magma body has the largest surface area (see Fig. 6). The initial expulsion event is accompanied by a pronounced pressure anomaly to accommodate the additional magmatic fluids which leads to a quasi-radial outward propagation involving an area much wider than the width of the cupola and affects the entire domain between magma chamber and surface (Fig. 7A). The critically stressed brittle crust almost immediately reaches the failure criterion and hydraulic fracturing enhances permeability to a few kilometers distance around the cupola. In the beginning, the high source rate maintains a pressure anomaly that keeps permeability at the maximum value of $10^{-14} \mathrm{~m}^{2}$ in the area surrounding the cupola.

The propagations of the thermal and solute front are decoupled, because the initially hot magmatic fluids lose heat to the surrounding colder host rock. While the thermal front has only progressed about $1 \mathrm{~km}$ from the cupola (Fig. 7E), magmatic salt has already reached the surface (Fig. 7I). With continuous expulsion, the area above the cupola is heated toward magmatic temperatures and the host rock starts to increasingly behave in a ductile manner resulting in decreasing permeability. As a consequence, the fluids exsolving from the magma are prevented from leaving the cupola, which leads to further increase in fluid pressure. With the transition from brittle to ductile behavior of the host rock, the stress state of the crust changes by relaxing differential stress, which leads to a transition of the failure criterion from near-hydrostatic to near-lithostatic conditions, meaning that the host rock is not fractured as easily as the near-critically stressed brittle crust.

The elevated fluid pressures lead to an increase in permeability, or rather work against the temperature-dependent permeability decrease, so that hydraulic fracturing starts from the same background permeability as in the brittle case, albeit now at near-lithostatic fluid pressures. As a result, the model develops a vertically extended zone dominated by high-pressure, high-temperature magmatic fluids and predominantly ductile rock behavior (Fig. 7A), hereafter referred to as the 'inner' part of the hydrothermal system with a hydrological divide. Fluid pressures episodically reach the failure criterion and release overpressure-permeability waves that ascend from the cupola to the current location of the hydrological divide. The snapshot after 800 years of simulation time (Fig. 7A) shows the establishment of this inner part of the magmatic fluid plume with one permeability wave developing at the cupola and an earlier one just about to release a surge of magmatic fluids to the brittle region surrounding it. 

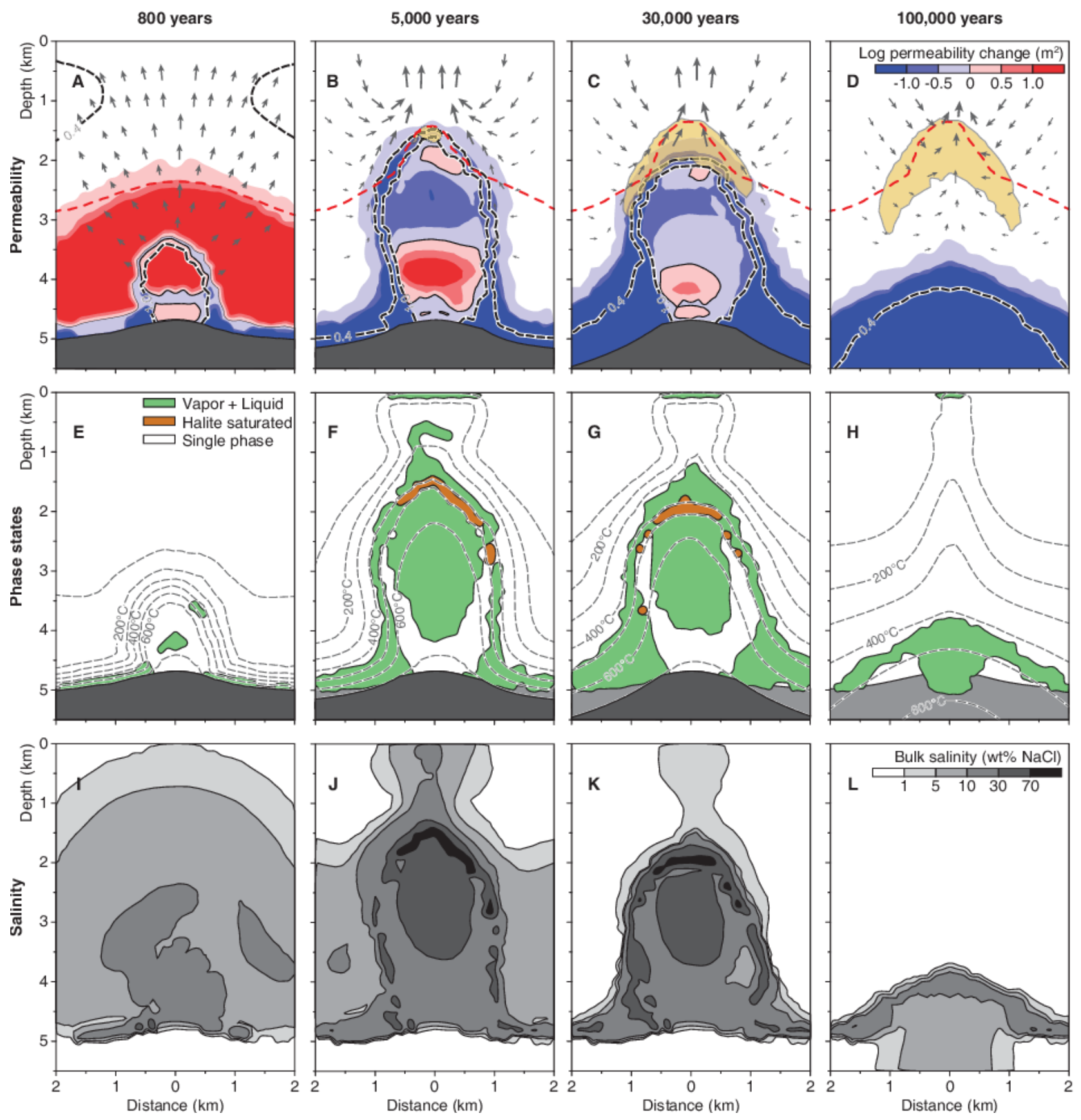

Figure 7. Temporal and spatial evolution of the hydrology of porphyry copper systems. A-D: Dynamic permeability changes in reference to the depth-dependent background profile (Fig. 1A) after 800, 5000, 30 000, and 100000 years of simulation time. The black-dashed lines show the pore fluid factor (fluid pressure divided by lithostatic pressure) with values below 0.4 indicating near-hydrostatic fluid pressures and values of 1.0 indicating near-lithostatic fluid pressures. Black arrows schematically show fluid flow in the dominantly brittle domain. The black solid lines show a vein volume potential of $10 \%$. The black area indicates the magma chamber. E-H: Temperature distribution and multiphase fluid states with light gray areas indicating liquid-vapor coexistence and dark gray areas halite-saturated fluids (vapor-halite, liquid-halite or vapor-liquid-halite coexistences). The black solid lines show a copper enrichment potential of 500. The black area indicates the magma chamber and the very light gray area the solidified pluton. I-L: Variations in bulk salinity of the fluid mixture including the solid halite phase. (Color versions of Figures 1 to 12 can be found in the on the online version of this article in Geofluids, 15). 
The wave-like behavior results from the parameterization of hydraulic fracturing by incremental permeability increase as a function of overpressure. Unless fluid supply can permanently maintain fluid pressures above lithostatic with the maximum permeability of $10^{-14} \mathrm{~m}^{2}$, fluid overpressure will be released periodically and permeability will be reduced to the background value or lower, followed by the next pressure build-up which will trigger the next wave. The frequency of the permeability waves depends on the fluid supply rate, which controls the rate of pressure increase at the cupola, and the exact parameterization of hydraulic fracturing, which describes the degree of permeability response to overpressure: changing the $\lambda^{2}$-dependence in Eq. 14 to a $\lambda$ - or $\lambda^{3}$-dependence leads to lower or higher frequencies, respectively. However, the location of the brittle-ductile transition and hydrological divide within the host rock is governed by the larger-scale balances of heat and mass fluxes and is therefore less dependent on the exact implementation.

The initial expulsion phase leads to intense fracturing within a wide radius around the cupola and a predicted vein volume potential of $10 \%$ reaching out to a depth of about $2 \mathrm{~km}$. With the continuous exsolution of magmatic fluids, the upper boundary of the ductile region extends to shallower depths, reaching a peak at about 5000 years of simulation time (Fig. 7B, F and J). By that time, the pressure anomaly in the brittle part of the domain has relaxed and a convection of predominantly meteoric fluids cools the overpressured high-temperature part of the magmatic fluid plume from the sides. This brittle domain with meteoric convection is hereafter referred to as the 'outer' part of the hydrothermal system. As the background permeability increases with shallower depth, this cooling effect increases toward the surface and the heat balance of ascending magmatic fluids and meteoric convection determines the round top of the predominantly ductile domain.

In the deeper parts of the system, the two hydrological systems are separated by a low-permeability zone that conductively transfers heat from the magmatic- to the meteoric-dominated part, where it is removed by convection of fluids at temperatures of 350 to $400^{\circ} \mathrm{C}$.

The snapshot after 5000 years captures an overpressure-permeability wave that ascends from the cupola toward the surface (Fig. 7B). At shallower levels, an earlier wave is about to reach the hydrological divide where the surge of magmatic fluids mixes with the convecting meteoric water. Here, the magmatic fluids experience a relatively sudden drop in pressure (from near-lithostatic to nearhydrostatic) and temperature (from about $500^{\circ} \mathrm{C}$ to $300^{\circ} \mathrm{C}$ ). While the ascent of the magmatic fluids is predominantly vertical, the surges at the hydrological divide can also have a significant horizontal component as the pressure gradient from lithostatic to hydrostatic is similarly sharp at the sides of the 
overpressured plume.

The repeated sealing-fracturing cycles lead to an increased vein density potential in the central hightemperature upflow zone (Fig. 7B). Copper enrichment potential starts to increase at the hydrological divide where conditions for porphyry mineralization at the stable temperature-pressure front are maintained with the sharp temperature drop from above 450 to below $350^{\circ} \mathrm{C}$.

Due to the high fluid pressures at the cupola, the magmatic fluids are injected in a single-phase state (Fig. 7F). Upon ascent, these primary fluids phase-separate into a low-salinity, low-density vapor and a high-salinity, high-density brine phase. As the two phases can physically separate from each other with the vapor phase rapidly ascending toward the surface, the bulk salinity of the fluid mixture increases to values between 30 and $70 \mathrm{wt} \% \mathrm{NaCl}$ (Fig. 7J). However, the high-pressure conditions allow a further upward movement of the heavy brine phase. At the hydrological divide, the high-salinity fluids saturate in solid halite due to the pressure drop, which moves the fluids from vapor-liquid coexistence to vaporhalite coexistence.

Solid halite is assumed to be immobile and to reduce the permeability available for the mobile phases liquid and vapor (Eq. 2), which can lead to a blocking effect triggering pulsating fluid flow behavior and salt accumulation in the crust (Weis et al. 2014). With the hydrological divide in place, however, the precipitated salt can subsequently be dissolved by the convecting meteoric fluids and transported toward the surface as moderately saline mixtures of magmatic and meteoric fluids. The upflow zone above the divide is close to the boiling curve of these moderately saline fluids (Fig. 7J), fluctuating between a two-phase zone that extends from the divide to the surface and two distinct two-phase fields with one right above the divide and one just underneath the surface (Fig. 7F).

While the magma chamber is generally cooled from the outer rim of the original outline inwards, the hydrothermal system above the cupola of the magma chamber prevents this part of the magma to be cooled and the location of the cupola remains constant for almost the entire fluid expulsion phase. With further inward crystallization, the surface area of the magma chamber decreases, which leads to a smaller rate of fluid production. In response, the heat balance of magmatic fluid supply and convective cooling moves the hydrological divide and therefore also the temperature-pressure front to greater depths (Fig. 7C, G and K). As a consequence, hydraulic fracturing becomes less intense and vein vol ume potential is only increased by minor amounts, while copper enrichment potential continues to accumulate, albeit at greater depths, extending the ore shell toward deeper levels. With this retreat, the 
model predicts that areas that have been overprinted by intense, barren stockwork veining at temperatures above $500^{\circ} \mathrm{C}$ in the early phases are now overprinted by copper-bearing veins forming at lower temperatures, which explains why copper is introduced at a later stage than the first generation of barren quartz (Landtwing et al. 2005).

This process continues until the magma chamber is fully crystallized (Fig. 7D, $\mathrm{H}$ and L). The remaining heat of the pluton drives thermal convection at moderately elevated temperatures and maintains an upflow zone passing through the deposit, which may lead to overprints of low-temperature alteration or redistribution of ore minerals.

\subsection{The influence of permeability range}

Permeability ranges at porphyry copper systems may be significantly higher than the ones obtained from tectonically active crust (Manning \& Ingebritsen 1999) and the average permeability value may rather be characterized by a depth-dependent profile of the perturbed crust (Ingebritsen \& Manning 2010). To investigate the influence of permeability range on the results, a simulation with the same general setup but permeability values of one order of magnitude higher have been conducted (Fig. 8). The background permeability profile is now calculated in reference to a log $k$ of -13 at $1 \mathrm{~km}$ depth instead of -14 as in Eq. 6. Likewise, temperature-dependent permeability is calculated in reference to a permeability of $10^{-13} \mathrm{~m}^{2}$, which is now also used as a maximum permeability value.

After 800 years, the thermal front has already progressed further than in the previous simulation (Fig. 8A, E and I). The snapshot captures the transition from the initial expulsion phase to the establishment of the hydrological divide separating the two regimes of fluid flow. In the uppermost part, fluids are still expelled radially outward, while some magmatic fluids traversing the hydrological divide at the top are cooled and sink back to greater depth where they become involved in the cooling mechanism that stabilizes the hydrological divide.

Fluid flow in the inner, high-pressure part is again dominated by overpressure-permeability waves, which now has a significantly smaller horizontal extent as in the simulations with lower permeabilities (Fig. 8A). The area of $10 \%$ vein volume potential is limited to this upflow zone, showing that hydraulic fracturing during the initial fluid expulsion phase is less drastic, because the overall higher permeability values are able to release the fluids more easily. 

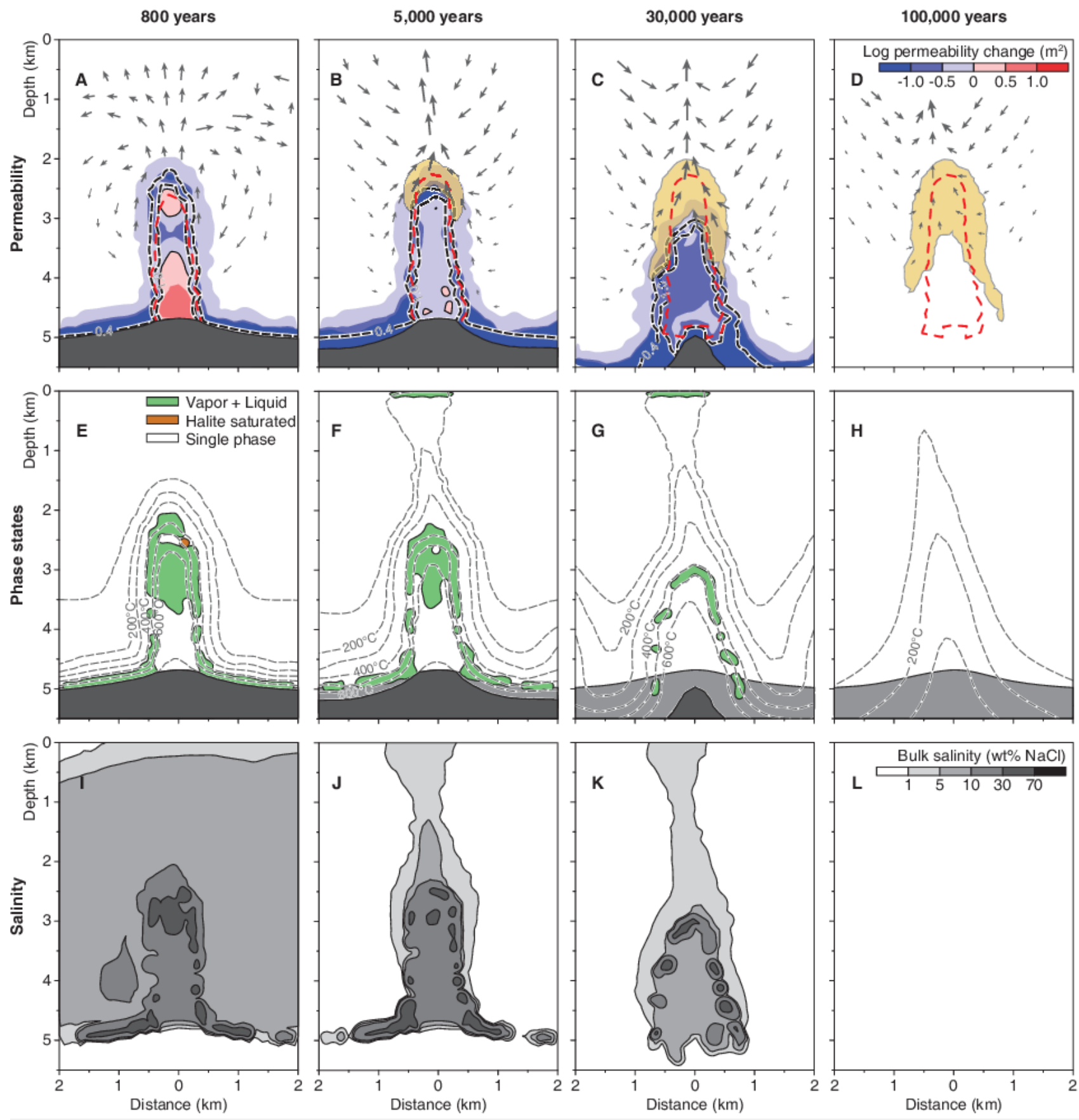

Figure 8. Temporal and spatial evolution of the hydrology of porphyry copper systems with higher permeabilities. A-D: Dynamic permeability changes in reference to the depth-dependent background profile of one order of magnitude high er than in Fig. 1A after 800, 5000, 30 000, and 100000 years of simulation time. The black-dashed lines show the pore fluid factor. Black arrows schematically show fluid flow in the dominantly brittle domain. The black solid lines show a vein volume potential of $10 \%$. The black area indicates the magma chamber. E-H: Temperature distribution and multiphase fluid states with light gray areas indicating liquid-vapor coexistence and dark gray areas halite-saturated fluids. The black solid lines shows a copper enrichment potential of 500. The black area indicates the magma chamber and the very light gray area the solidified pluton. I-L: Variations in bulksalinity of the fluid mixture including the solid halite phase.

As in the simulation with lower permeabilities, the magmatic fluids are injected in the single-phase state and phase-separate upon ascent (Fig. 8E), leading to an increase in bulk salinity (Fig. 8I). The simulation 
also develops the same sharp temperature-pressure front at the hydrological divide. However, halite saturation is less pronounced at the transition, because convection in the outer, brittle part is more effective in removing the magmatic salt injected with the incoming fluid surges from the inner, highpressure part due to the higher permeability of the host rock.

After 5000 years, the characteristic hydrology with the inner part being dominated by magmatic fluids and the outer part dominated by meteoric fluids is fully developed (Fig. 8B, F and J). Copper starts to become enriched around the temperature-pressure front, which is already retreating to deeper levels, while vein density only increased slightly as compared to Fig. 8A. The expelled magmatic fluids still phase-separate upon ascent. However, the increase in bulk salinity has become less dramatic and fluids do not saturate in solid halite anymore.

After 30000 years, phase separation is limited to the relatively narrow region of the hydrological divide (Fig. 8G). The gradual retreat of the associated precipitation front leads to an elongated, cylindrical shape of the copper enrichment zone (Fig. 8C). With decreasing source rate and due to the higher background permeability, the addition of magmatic fluids can be accommodated with the given background permeability profile and no hydraulic fracturing, and consequently, also no overpressurepermeability waves develop anymore. After 100000 years of simulation time, the magma chamber has fully crystallized, all the magmatic salt has been flushed through the surface and the remaining heat only maintains a low-temperature hydrothermal system of a single-phase fluid (Fig. 8D, H and L).

\subsection{The influence of salinity}

The hydrology of porphyry copper systems as described previously is controlled by nonlinear fluid properties and nonlinear feedbacks of rock permeability, and the complexity of the system makes it difficult to single out the influence of individual components. $\mathrm{NaCl}$ is known to be essential for ore formation and all fluid inclusion studies at porphyry deposits document low-salinity vapors and highsalinity brines (Bodnar et al. 2014). To single out the effect of salinity, the following simulation investigates to which extent the permeability model now governs the hydrology when fluid properties of pure water instead of salt water are used. The results also provide an end-member case for magmas with less saline fluid contents. The salinity of exsolved fluids may also vary in time as a function of composition and intrusion depth, with either the early or the late phase including more dilute fluids than the $10 \mathrm{wt} \% \mathrm{NaCl}$ used in the previous simulations (Cline \& Bodnar 1991). 
The pure water simulation starts with a similar fluid expulsion phase as in the salt water simulation (Fig. 7A) with quasi-radial outward propagation of the fluids and hydraulic fracturing of the brittle domain in a wide area around the cupola (Fig. 9A). The inner part with near-lithostatic fluid pressures and high temperatures has already progressed slightly further than in the salt-water simulations (Fig. 9A and E). After 5000 years, the system also self-organizes into the two distinct fluid domains (Fig. 9B). However, the hydrological divide stabilizes at a greater depth. Fluids stay in the single-phase field within the inner part due to the high fluid pressures (Fig. 9F).
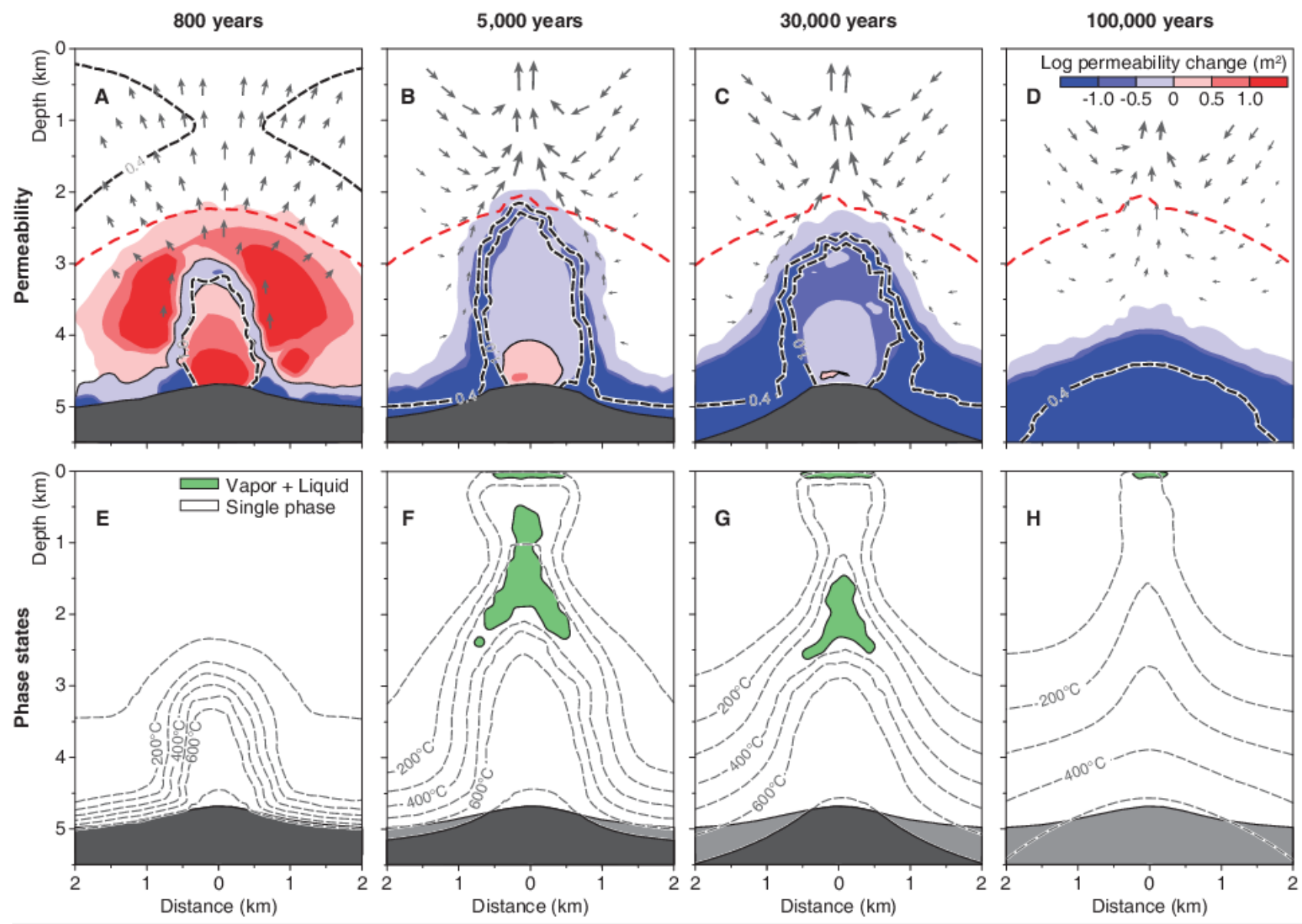

Figure 9. Temporal and spatial evolution of the hydrology of porphyry copper systems without magmatic salt. A-D: Dynamic permeability changes in reference to the depth-dependent background profile after 800,5000,30 000, and 100000 years of simulation time. The black dashed lines show the pore fluid factor. Black arrows schematically show fluid flow in the dominantly brittle domain. The black solid lines show a vein volume potential of $10 \%$. The black area indicates the magma chamber. E-H: Temperature distribution and two-phase fluid states with light gray areas indicating liquid-vapor coexistence. The black area indicates the magma chamber and the very light gray area the solidified pluton.

With the transition to the near-hydrostatically pressured domain and with cooling due to mixing with the convecting meteoric waters, the fluids phase-separate into liquid and vapor and develop a boiling zone spanning almost the entire distance from the hydrological divide to the surface. 
Again, with further inward crystallization, the hydrological divide retreats to greater depths (Fig. 9C and G). After 30000 years of simulation time, the two-phase area is limited to the center part directly above the divide and directly beneath the surface (Fig. 9G). Hydraulic fracturing is less drastic than in the simulation with salt water throughout the simulation and after 30000 years the background permeability profile is (mostly) sufficient to accommodate the additional amount of magmatic fluids (Fig. 9C).

\subsection{The influence of volcano topography}

Fluid expulsion in the simulation with volcano topography follows the same principles as the simulations before. The ascending magmatic fluids develop a similar upflow zone under high temperatures and near-lithostatic pressures as well as the sealing-fracturing cycles described as overpressure-permeability waves (Fig. 10). In the brittle domain, however, the higher fluid pressures imposed by the fluid-saturated volcano and the resulting outward-oriented pressure gradient lead to an opposite flow direction for the convecting meteoric fluids.

The round top of the hydrological divide is now shaped by down-flowing meteoric fluids that mix with the ascending magmatic fluids and further descend along the hydrological divide. The reversed convection pattern enhances the steepness of the temperature front, as the descending meteoric fluids in the center directly mix with the upflowing hot magmatic fluids without being pre-heated at the sides of the magmatic fluid plume as in the simulations without volcanotopography. Once the fluid mixture is heated to temperatures of $300-400^{\circ} \mathrm{C}$, however, the temperature is maintained as the fluids flow along the transition from brittle to ductile rock behavior. As the convection detaches from this transition region and flows upward toward the surface, the fluids cool to temperatures of $100-200^{\circ} \mathrm{C}$. At the base of this topography-driven convection cell, further meteoric convection cells mining heat from the outer parts of the crystallizing magma chamber merge into the main upflow zones.

Salinity variations in the center are similar to the simulation with the same permeability profile in reference to $10^{-14} \mathrm{~m}^{2}$ at $1 \mathrm{~km}$ (Fig. 10C). However, in the peripheral parts of the domain, significant amounts of magmatic salt are still retained within the crust. This salt mass has been expelled during the initial phases of fluid release and is now located in areas outside of the main convection cell.

Increasing the permeability profile by an order of magnitude has a narrowing effect on the inner upflow zone (Fig. 11) and determines the shape of the predicted ore body. While in the previous simulation copper is enriched within a wider, horizontally oriented shell (Fig. 10A), the high-permeability profile 
produces a narrower, vertically extended shell (Fig. 11A). With higher permeabilities, the magma chamber has already crystallized further inward moving down from the volcanic edifice, cooling the top after 30000 years, and the hydrological divide has retreated to greater depths with decreasing source rate.
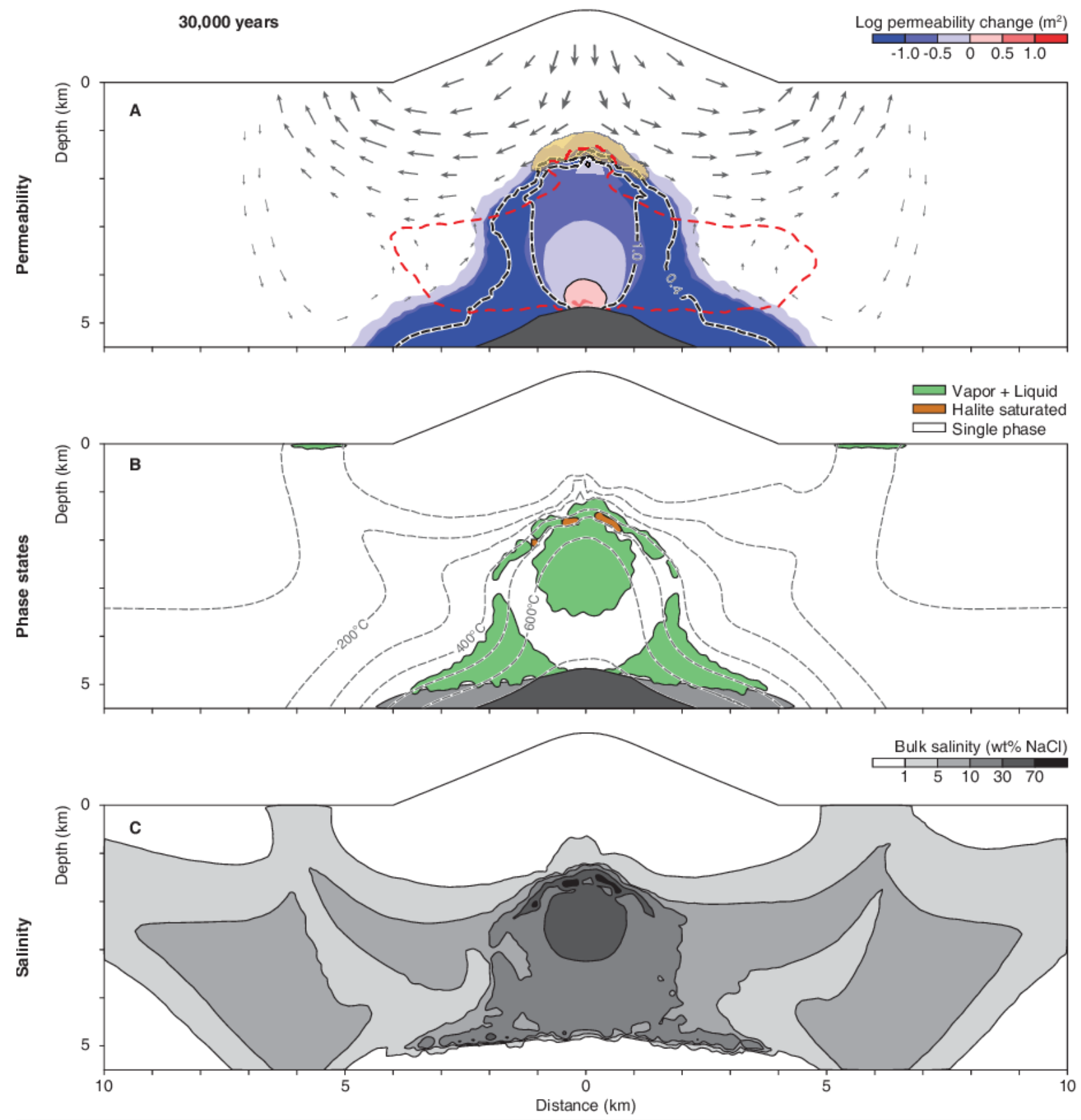

Figure 10. Snapshot of the hydrology of porphyry copper systems with volcano topography after 30000 years of simulation time. A: Dynamic permeability changes in reference to the depth-dependent background profile. The black-dashed lines show the pore fluid factor. Black arrows schematically show fluid flow in the dominantly brittle domain. The black solid lines show a vein volume potential of $10 \%$. The black area indicates the magma chamber. B: Temperature distribution and multiphasefluid states with light gray areas indicating liquid-vapor coexistence and dark gray areas halite-saturated fluids. The black solid line shows a copper enrichment potential of 500. The black area indicates the magma chamber and the very light gray area the solidified pluton. C: Variations in bulk salinity of the fluid mixture including the solid halite phase. 

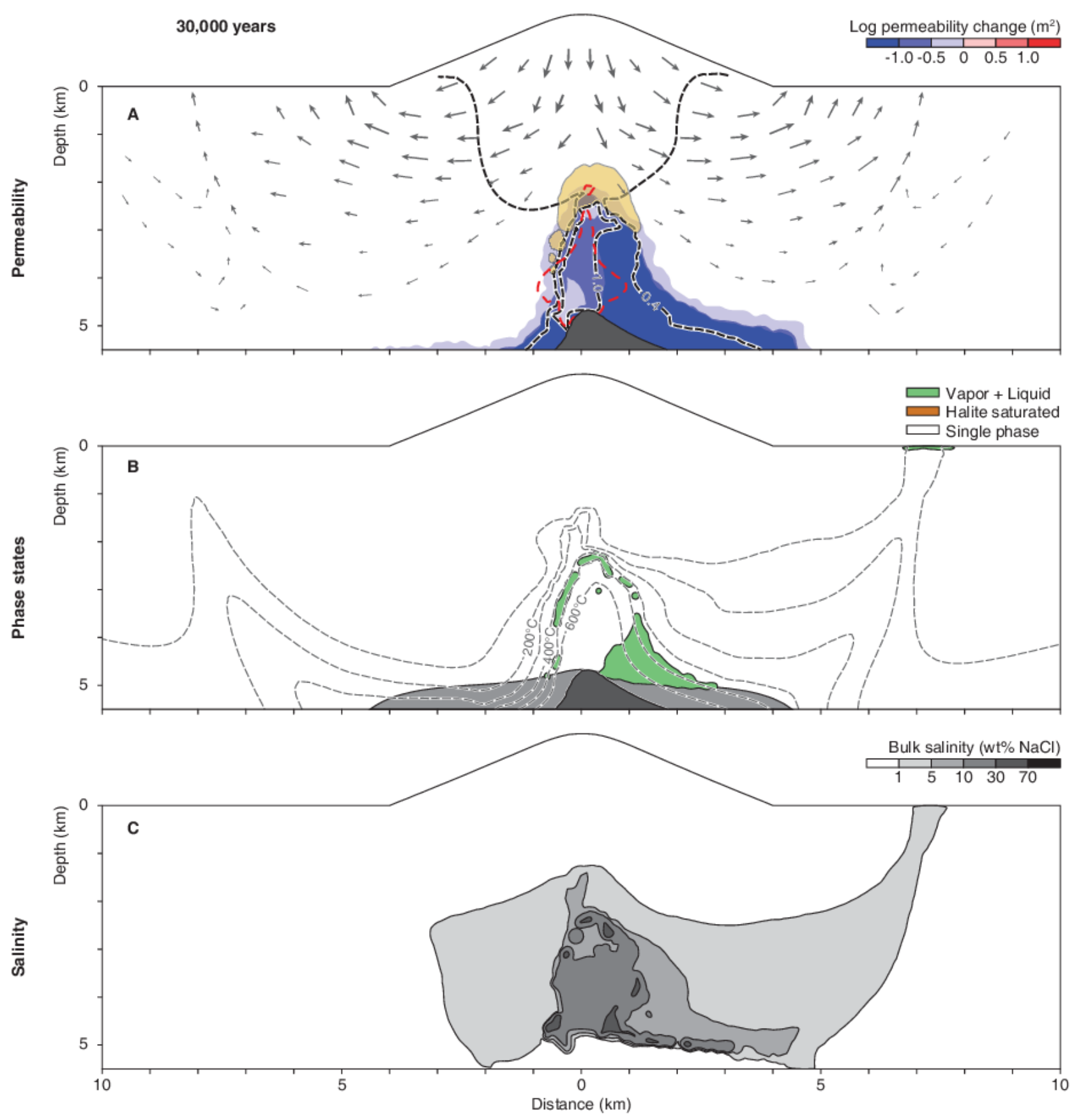

Figure 11. Snapshot of the hydrology of porphyry copper systems with volcano topography and higher permeability profile after 30000 years of simulation time. A: Dynamic permeability changes in reference to the depth-dependent background profile of one order of magnitude higher than in Fig. 1A. The black-dashed lines show the pore fluid factor. Black arrows schematically show fluid flow in the dominantly brittle domain. The black solid lines show a vein volume potential of $10 \%$. The black area indicates the magma chamber. B: Temperature distribution and multi-phase fluid states with light gray areas indicating liquid-vapor coexistence. The black solid line shows a copper enrichment potential of 500. The black area indicates the magma chamber and the very light gray area the solidified pluton. C: Variations in bulk salinity of the fluid mixture including the solid halite phase.

Meteoric convection is entirely dominated by fluids and the flanks of the inner, high-pressure part and flowing outward to rise back to the surface at about $7 \mathrm{~km}$ distance from the center. The peripheral convection cells have moved further outward as compared to the lower-permeability simulations and 
the location where these convection cells merge mark the upflow with the highest temperatures and salinities (Fig. 11B and C).

The asymmetric evolution of the hydrothermal system reflects the increasingly dynamic behavior with higher permeabilities. Magmatic fluids traversing the hydrological divide develop a preference toward one side of the two-dimensional modeling domain, which is enhanced by the nonlinear behavior of the hydrothermal system. In the early phases of the system, discharge mainly occurred to the left side, which explains the stronger cooling and the increased copper enrichment along the left limb. At later stages, however, the hydrothermal system switches to preferred discharge at the right side, as indicated by the higher temperatures and salinities of the upflow zone (Fig. 11B and C).

\section{Discussion}

The distribution of copper enrichment potential and vein volume potential predicted by the model matches with observed copper ore grades and vein densities at porphyry deposits, indicating that porphyry copper ore shells form at stable temperature-pressure fronts at a hydrological divide between a hot overpressured upflow zone of magmatic fluids to a colder brittle domain with convection of meteoric fluids (see also Weis et al. 2012). Varying rock properties by using overall higher permeability values has a significant effect on the dimensions of the deposit (Fig. 7 and 8). The ore shell and the area of intense quartz veining are much narrower and concentrated. The limbs of the shell at the sides become steeper and partially merge, forming a vertically extended, cylindrical shaped ore body with only a minor barren core at the deeper ends.

Simulations including a volcano at the surface show that topography-driven flow has a significant effect on the hydrology as it reverses the direction of the meteoric convection, leading to discharge locations at epithermal conditions at distances as far as $7 \mathrm{~km}$ away from the volcanic center. The predicted deposits in the porphyry environment, however, are comparable with the simulations with flat topography (Fig. 7-11), with only a tendency toward wider ore shells.

The entire ore-forming event is predicted to last between 50000 and 100000 years (Fig. 12A), which is in good agreement with recent high-precision geochronology and earlier modeling studies (Cathles 1977; Norton \& Knight 1977; Hayba \& Ingebritsen 1997; Driesner \& Geiger 2007; von Quadt et al. 2011). 

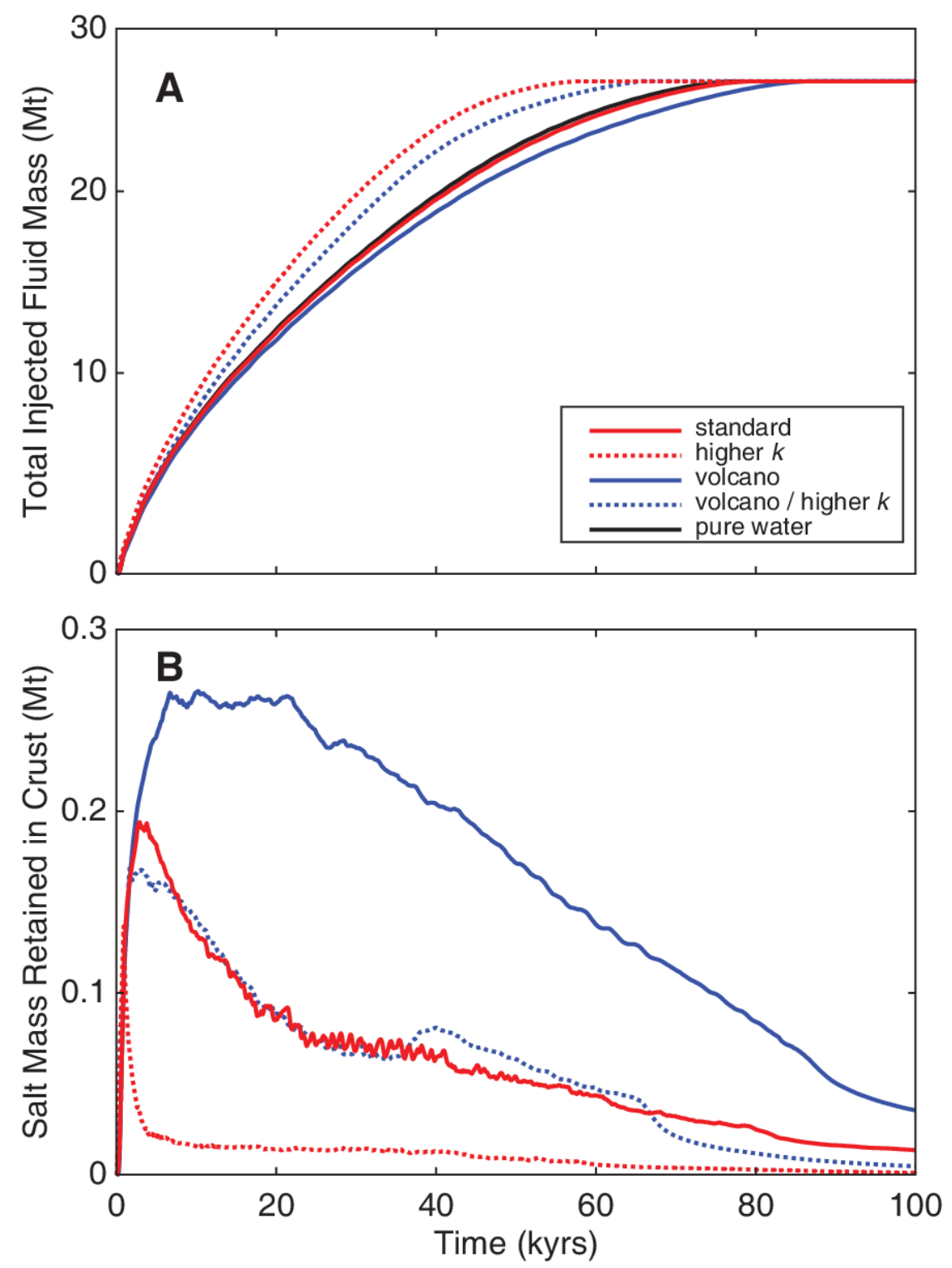

Figure 12. Fluid expulsion and magmatic salt. A: Temporal evolution of injection of magmatic fluid mass. B: Temporal evolution of salt mass retained in the modeling domain.

\subsection{Saline fluid flow and rock permeability}

The interplay between saline fluid flow and rock permeability controls the self-organization of the system. In the simulations, the brittle-ductile transition is assumed to start at a temperature of $360^{\circ} \mathrm{C}$, which is in agreement with borehole measurements at active geothermal systems, where fluid pressures begin to rise at that temperature (Fournier 1991). A similar behavior of rock properties has been inferred to control hydrothermal convection at mid-ocean ridges (Cathles 1993). At the same temperature, fluid properties of (salt) water also develop the strongest buoyancy-driven upward force or fluxibility, leading to an optimized mass and energy transport as can also been shown for mid-ocean- 
ridge hydrothermal systems (Jupp \& Schultz 2000; Coumou et al. 2008, 2009a).

Varying fluid properties by using pure water as a proxy for magmatic fluids expelled from the magma chamber shows that $\mathrm{NaCl}$ has an important effect on the dynamics of the system. The increase in fluid volume due to phase separation at high temperatures and fluid pressures during the ascent of saltwater fluids leads to more drastic permeability changes and more intense fracturing, which moves the hydrological divide to much shallower crustal levels than in the pure water case.

The development of a hydrological divide also provides an important mechanism to transport magmatic salt through the crust and to discharge it at the surface (Fig. 12). The magma chamber has a volume of about $95 \mathrm{~km}^{3}$ in three dimensions (Fig. 6) and exsolves a total amount of about 13 Gt of fluids. Scaled to the two-dimensional section, a total of about $27 \mathrm{Mt}$ of fluid mass is injected during the simulation (Fig. 12A), including $2.7 \mathrm{Mt}$ of magmatic salt. Considering the porosity of $5 \%$ of the modeling domain, this amount of salt would be enough to fill the entire pore space above the cupola in an area of $5 \mathrm{~km}$ width, i.e. more than the excerpts of Figs 7 and 8.

The hot, salty fluids will inevitably phase-separate and saturate in solid halite, either by continuous accumulation of a heavy brine phase residing at depth or by phase transition to the vapor-halite coexistence field with decreasing fluid pressures upon ascent of the hot fluids. Simulations with magmatic degassing of $\mathrm{H}_{2} \mathrm{O}-\mathrm{NaCl}$ fluids with static, uniform permeabilities show that magmatic salt is not easily vented through the crust and that accumulation of solid halite can lead to a pulsating fluid flow in saline magmatic-hydrothermal systems (Weis et al. 2014). However, the presence of a solid halite phase has only been inferred in very few fluid inclusion studies or indirectly shown by the socalled halite trend (Cloke \& Kesler 1979; Muntean \& Einaudi 2000; Lecumberri-Sanchez et al., 2015).

The salt mass accumulated in the crust over the simulation time for the porphyry model described here increases to a maximum during the first 5000 years (Fig. 12B). The maximum is associated with the establishment of the hydrological divide and the change from fluid expulsion to convection in the outer, hydrostatically pressured domain. Depending on the background permeability profile, these convecting, cooling fluids are initially saline, because a significant fraction represent reheated magmatic fluids (see Fig. 7J).

After the maximum in salt accumulation, the salt mass retained in the crust decreases steadily even though more dissolved salt is added at the cupola. Due to the higher permeabilities in the uppermost 
part of the domain, the fluids of the upflow zone stay moderately saline, which means that they are not too dense, so that they can still move upward and transport more salt out of the system than is injected at the cupola. In particular, the high-permeability simulation shows that the meteoric convection is not only an important cooling agent for the porphyry copper system but also an efficient diluting agent that prevents the system from becoming salt oversaturated.

\section{2. $\quad$ Further dynamics}

The dynamic permeability model still uses a number of simplifications and general assumptions. Resolving further dynamics will lead to a more detailed understanding of the system. Both stress field and strain rate may vary in space and time, which will have an impact on failure criteria and the location of the brittle-ductile transition. Pre-existing fractures or larger fault zones may play an important role to alter hydrological pathways and stress patterns, especially in the uppermost part of the domain.

The model assumes that the host rock is critically stressed and permeability follows a characteristic profile for tectonically active crust under normal-faulting conditions. However, the crust may also be dominated by less permeable rocks, which may not be critically stressed, or the tectonic setting may lead to strike-slip conditions. These properties of the host rock may further vary in space and time, due to both external changes and the evolution of the porphyry system itself. All of these factors are likely to influence the hydrothermal system, in particular the convection of the meteoric fluids within the brittle domain. Their individual effects are hard to predict but could be investigated with further simulations.

Except for halite precipitation and dissolution, the model currently does not explicitly account for geochemical feedbacks on porosity and permeability. In particular, quartz precipitation and dissolution can have an important effect on fluid flow and hydrofracturing, which is parameterized as an incremental permeability increase here but ultimately requires a description that is able to capture the actual physical process. Likewise, the process of fracture closure and vein sealing requires further constraints. In the nominally ductile domain, the parameterization as immediate closure ensured that overpressure can be released temporarily. This mechanism can be explained by rapid vein sealing with quartz precipitation and matches the observations at porphyry deposits. In the brittle domain, however, permeability decay after a permeability-creating event may be considerably slower (Ingebritsen \& Manning 2010). Fluid-rock reaction can also alter the host rock and lead to changes in rock properties, which may affect the hydrothermal system. Furthermore, an impermeable carapace at 
the cupola may lead to temporary accumulation of magmatic fluids and episodic injections into the host rock together with magma, which may also result in repeated dike injections as observed at many porphyry deposits (e.g., Dilles 1987; Sillitoe 2010).

Wave-like behavior of fluid flow through the crust has been described in a number of hydrogeological settings. Metamorphic and sedimentary environments may generate compaction-driven porosity waves (Connolly \& Podladchikov 1998; Appold \& Nunn 2002; Connolly 2015). Earthquakes have been inferred to trigger fault-valve behavior of fast fluid flow along faults (Sibson 1987; Miller et al. 2004),

which may lead to the formation of mesothermal gold deposits (e.g., Sibson et al. 1988; Micklethwaite et al. 2015). Solitary waves may facilitate fluid transport from deep, overpressured regions to shallower levels in hydrocarbon reservoirs and accretionary wedges (e.g., Revil \& Cathles 2002; Bourlange \& Henry 2007; Joshi et al. 2012). Permeability has also been described as a toggle switch between extremely high and low values depending on whether fluid pressures meet the failure condition or not, leading to the development of an interconnected flow network in fractured rocks (Miller \& Nur 2000). All of these processes have in common that they regard permeability and/or porosity as a dynamic parameter.

\subsection{Relations to active hydrothermal systems}

The convection system above the hydrological divide resembles high-enthalpy geothermal systems, where upflow follows a boiling-curve-with-depth profile. However, the relatively high permeability in the uppermost part and the permeability decrease with depth lead to a stronger cooling of the heated fluid due to convection of colder fluids at shallower crustal levels. Numerical simulations have shown that the highest enthalpies are achieved for permeabilities near $10^{-15} \mathrm{~m}^{2}$ that optimize the balance between heat conduction from the source and advection by the convecting fluids (Hayba \& Ingebritsen 1997; Driesner \& Geiger 2007). In the presented simulations, episodic magmatic fluid surges can provide additional heat to temporarily maintain the boiling-with-depth profile.

The hydrological divide as described here separates the actual heat source, the magma chamber, from the base of the high-enthalpy system by several kilometers in the vertical direction. This vertical profile is a result of fluid release from the magma chamber, which points to significantly different styles of the driving heat source for hydrous magmas in subduction settings, such as in the Taupo Volcanic Zone (TVZ), as compared to anhydrous magmas at constructive plate margins, such as in Iceland. Without the release of magmatic fluids, the base of the hydrothermal system will remain closer to the magma 
chamber, as documented by simulations of subaerial and submarine hydrothermal systems (e.g., Cathles 1977; Norton \& Knight 1977; Hayba \& Ingebritsen 1997; Coumou etal. 2009b; Gruen etal. 2014; Weis 2014; Weis et al. 2014).

At the TVZ, the brittle-ductile transition is generally inferred to be located at 6-7 $\mathrm{km}$ depth while the hydrothermal systems are predominantly located within the uppermost $3 \mathrm{~km}$ of the crust (Bertrand et al. 2012). In between, at 3-7 km depths, recent magnetotelluric data show vertically extended lowresistivity zones with a width of a few kilometers, interpreted to represent convection plumes connecting the near-surface hydrothermal activity with an underlying magmatic system at depths of about $10 \mathrm{~km}$ (Bertrand et al. 2012). The dimensions and depth ranges of these structures resemble the hydrology of the porphyry systems described in this study, where the high-temperature, nearlithostatically pressured part forms the base of the high-enthalpy system at shallow depths.

The different styles of heat source may also shed light on so-called supercritical geothermal resources (referring to the critical point of pure water), which aim at tapping fluids with enthalpies of $3 \mathrm{MJ} \mathrm{kg}^{-1}$ instead of 1.5 MJ kg-1 typical for high-enthalpy systems. Supercritical geothermal resources are currently explored in volcanic areas such as the Krafla site in Iceland in the roots of high-enthalpy systems (Fridleifsson \& Elders 2005; Elders et al. 2011), which are likely to be located close to the magma chamber in tectonic settings with predominantly anhydrous magmatism. Also, the inferred brittle-ductile transition may be associated with higher temperatures for basaltic rocks than the 360$500^{\circ} \mathrm{C}$ assumed here (Fournier 1999; Scott et al. 2015). In contrast, according to the simulations presented here, supercritical conditions in association with more felsic, hydrous magmatism only develop below the hydrological divide and the targeted semi-brittle, semi-ductile area is limited to a narrow region dividing the two hydrological systems (Weis \& Driesner 2013). The simulations suggest that the rock in the upflow zone in the roots of high-enthalpy systems may behave in a ductile (plastic, viscous) way, which relates to further geothermal projects, where the feasibility of injecting fluids into ductile rock is being investigated (Japan Beyond Brittle Project 2014).

Episodic ground deformations (bradyseism) at active volcanic regions are also closely related to the processes described here (Bodnar et al. 2007). Deformation is not modeled in our simulations, but the dynamics of the high-temperature, high-pressure domain with their overpressure-permeability waves and episodic surges of magmatic fluids are likely to also cause ground deformations, which have been quantified in other approaches that assumed comparable driving forces (e.g. Hutnak et al. 2009). 
Excess degassing at active volcanos refers to the observation that the amount of volatiles released through venting is larger than the volatile contents of the erupted magma and the volcanic conduit (Shinohara 2008). The simulations provide a mechanism for keeping the location of an initial cupola by continuous heating and thereby locally preventing cooling from the outside, which may help accumulate fluids from a larger source pluton. The modeling also describes how the fluids can ascend through the overlying rock within a focused, vertically extended upflow zone.

\section{Conclusions}

The dynamic interplay between saline fluid flow and rock permeability controls the evolution of magmatic-hydrothermal ore deposits. Numerical simulations indicate that porphyry copper ore shells form at a stable temperature-pressure front, dividing a hot inner upflow zone of magmatic fluids under near-lithostatic fluid pressures in a nominally ductile domain from colder surroundings dominated by meteoric convection under near-hydrostatic fluid pressures in a brittle domain. This hydrological divide provides both a cooling and diluting mechanism for saline magmatic fluids expelled from a crystallizing upper crustal magma chamber.

The permeability range influences the time scale of ore formation as well as the shape of the ore body and the distribution of vein density. With higher permeability profiles, the model predicts narrower, vertically extended ore shells. The salinity of the fluids influences the intensity of hydraulic fracturing due to phase separation within the upflow zone and affects the depth of ore formation. The selforganization into the hydrological divide also ensures that magmatic salt can be transported out of the domain with convection of meteoric fluids instead of being accumulated in heavy brines and solid halite within the crust. With a volcano topography above the hydrothermal system, the direction of flow in the meteoric convection cell reverses, leading to an even sharper temperature gradient at the top of the porphyry system and diverting the upflow zone at epithermal conditions to the flanks of the volcano, at distances of up to $7 \mathrm{~km}$ from the volcanic center.

The simulations further suggest that a hydrological divide maintained by magmatic fluid release in tectonic settings with felsic, hydrous magmatism can separate the base of high-enthalpy geothermal systems from the magma chamber as a driving heat source by several kilometers in the vertical direction. This upflow zone is characterized by fluid flow through nominally ductile rock with temporary embrittlement due to hydraulic fracturing and could serve as a source region for so-called supercritical geothermal systems. In general, the simulations support the concept of crustal 
permeability as a dynamic property evolving from an intimate interplay of fluid flow and rock permeability.

\section{Acknowledgements}

Many thanks to Stephen Cox and a second reviewer, the editors of Geofluids and the Special Issue on crustal permeability as well as Thomas Driesner and Christoph Heinrich for helpful comments and discussions on the manuscript. The work has been supported by the Swiss National Science Foundation within various funding periods.

\section{References}

Appold MS, Nunn JA (2002) Numerical models of petroleum migration via buoyancy-driven porosity waves in viscously deformable sediments. Geofluids, 2, 233-47.

Bertrand EA, Caldwell TG, Hill GJ, Wallin EL, Bennie SL, Cozens N, Onacha SA, Ryan GA, Walter C, Zaino A, Wameyo P (2012) Magnetotelluric imaging of upper-crustal convection plumes beneath the Taupo Volcanic Zone, New Zealand. Geophysical Research Letters, 39, L02304.

Bodnar RJ, Cannatelli C, De Vivo B, Lima A, Belkin HE, Milia A (2007) Quantitative model for magma degassing and ground deformation (bradyseism) at Campi Flegrei, Italy: implications for future eruptions. Geology, 35, 791-4.

Bodnar RJ, Lecumberri-Sanchez P, Moncada D, Steele-Maclnnis M (2014) Fluid inclusions in hydrothermal ore deposits. In: Treatise on Geochemistry (Second Edition) (eds Holland HD, Turekian KK), pp. 119-42. Elsevier, Oxford.

Bourlange S, Henry P (2007) Numerical model of fluid pressure solitary wave propagation along the decollement of an accretionary wedge: application to the Nankai wedge. Geofluids, 7, 323-34.

Cathles LM (1977) An analysis of the cooling of intrusives by ground-water convection which includes boiling. Economic Geology, 72, 804-26.

Cathles L (1993) A capless 350 C flow zone model to explain megaplumes, salinity variations, and high-temperature veins in ridge axis hydrothermal systems. Economic Geology, 88, 1977-88.

Cline JS, Bodnar RJ (1991) Can economic porphyry copper mineralization be generated by a typical calc-alkaline melt. Journal of Geophysical Research-Solid Earth and Planets, 96, 8113-26.

Cloke PL, Kesler SE (1979) Halite trend in hydrothermal solutions. Economic Geology, 74, 182331.

Connolly JAD (2015) An analytical solution for solitary porosity waves: implications for dynamic 
permeability and fluidization of ductile rock. Geofluids, 15, 269-92.

Connolly JAD, Podladchikov YY (1998) Compaction-driven fluid flow in viscoelastic rock. Geodinamica Acta, 11, 55-84.

Connolly JAD, Podladchikov YY (2004) Fluid flow in compressive tectonic settings: implications for midcrustal seismic reflectors and downward fluid migration. Journal of Geophysical Research-Solid Earth, 109, B04201.

Coumou D, Driesner T, Heinrich CA (2008) The structure and dynamics of mid-ocean ridge hydrothermal systems. Science, 321, 1825-8.

Coumou D, Driesner T, Geiger S, Paluszny A, Heinrich CA (2009a) High-resolution threedimensional simulations of mid-ocean ridge hydrothermal systems. Journal of Geophysical ResearchSolid Earth, 114, B07104.

Coumou D, Driesner T, Weis P, Heinrich CA (2009b) Phase separation, brine formation, and salinity variation at Black Smoker hydrothermal systems. Journal of Geophysical Research-Solid Earth, 114, B03212.

Cox SF (2005) Coupling between deformation, fluid pressures, and fluid flow in ore-producing hydrothermal systems at depth in the crust. Economic Geology, 100 th Anniversary Volume, 39-75.

Cox SF (2010) The application of failure mode diagrams for exploring the roles of fluid pressure and stress states in controlling styles of fracture-controlled permeability enhancement in faults and shear zones. Geofluids, 10, 217-33.

Dilles JH (1987) The petrology of the Yerington Batholith, Nevada: evidence for the evolution of porphyry copper ore fluids. EconomicGeology, 82, 1750-89.

Driesner T (2007) The system $\mathrm{H}_{2} \mathrm{O}-\mathrm{NaCl}$. Part II: correlations for molar volume, enthalpy, and isobaric heat capacity from 0 to 1000 degrees C, 1 to 5000 bar, and 0 to $1 \mathrm{X}-\mathrm{NaCl}$. Geochimica Et Cosmochimica Acta, 71, 4902-19.

Driesner T, Geiger S (2007) Numerical simulation of multiphase fluid flow in hydrothermal systems. In: Fluid-Fluid Interactions (eds Liebscher A, Heinrich CA), vol. 65, pp. 187-212. Mineralogical Soc Amer, Chantilly. Driesner T, Heinrich CA (2007) The system $\mathrm{H}_{2} 0-\mathrm{NaCl}$. Part I: correlation formulae for phase relations in temperature-pressure -composition space from 0 to 1000 degrees $C, 0$ to 5000 bar, and 0 to $1 \mathrm{X}-\mathrm{NaCl}$. Geochimica Et Cosmochimica Acta, 71, 4880-901.

Elders WA, Frioleifsson GO, Zierenberg RA, Pope EC, Mortensen AK, Guomundsson A, Lowenstern JB, Marks NE, Owens L, Bird DK, Reed M, Olsen NJ, Schiffman P (2011) Origin of a rhyolite that intruded a geothermal well while drilling at the Krafla volcano, Iceland. Geology, 39, 231-4.

Fournier RO (1991) The transition from hydrostatic to greater than hydrostatic fluid pressure in presently active continental hydrothermal systems in crysalline rock. Geophysical Research Letters, 18, 
955-8.

Fournier RO (1999) Hydrothermal processes related to movement of fluid from plastic into brittle rock in the magmatic-epithermal environment. Economic Geology, 94, 1193-211.

Fridleifsson G0, Elders WA (2005) The Iceland Deep Drilling Project: a search for deep unconventional geothermal resources. Geothermics, 34, 269-85.

Gruen G, Weis P, Driesner T, Heinrich CA, de Ronde CEJ (2014) Hydrodynamic modeling of magmatic-hydrothermal activity atsubmarine arc volcanoes, with implications for ore formation. Earth and Planetary Science Letters, 404, 307-18.

Gustafson LB, Hunt JP (1975) Porphyry copper deposit at El Salvador, Chile. Economic Geology, 70, 857-912.

Haar L, Gallagher JS, Kell GS (1984) NBS/NRC Steam Tables: Thermodynamic and Transport Properties and Computer Programs for Vapor and Liquid States of Water in SI Units, p. 320.

Hemisphere Publishing Corporation, Washington, New York, London.

Hanson RB (1995) The hydrodynamics of contact-metamorphism. Geological Society of America Bulletin, 107, 595-611.

Hayba DO, Ingebritsen SE (1997) Multiphase groundwater flow near cooling plutons. Journal of Geophysical Research, 102,12235-52.

Hedenquist JW, Lowenstern JB (1994) The role of magmas in the formation of hydrothermal oredeposits. Nature, 370, 519-27.

Hedenquist JW, Arribas A, Reynolds TJ (1998) Evolution of an intrusion-centered hydrothermal system: Far Southeast-Lepanto porphyry and epithermal $\mathrm{Cu}-\mathrm{Au}$ deposits, Philippines. Economic Geology, 93, 373-404.

Heinrich CA, Candela PA (2014) Fluids and ore formation in the earth's crust. In: Treatise on Geochemistry (Second Edition) (eds Holland HD, Turekian KK), pp. 1-28. Elsevier, Oxford.

Henley RW, Ellis AJ (1983) Geothermal systems ancient and modern - a geochemical review. Earth-Science Reviews, 19, 1- 50.

Herzarkhani A, Williams-Jones AE, Gammons CH (1999) Factors controlling copper solubility and chalcopyrite deposition in the Sungun porphyry copper deposit, Iran. Mineralium Deposita, 34, 770-83.

Hezarkhani A, Williams-Jones AE (1998) Controls of alteration and mineralization in the Sungun porphyry copper deposit, Iran: evidence from fluid inclusions and stable isotopes. Economic Geology, 93, 651-70.

Hutnak M, Hurwitz S, Ingebritsen SE, Hsieh PA (2009) Numerical models of caldera deformation: effects of multiphase and multicomponent hydrothermal fluid flow. Journal of Geophysical ResearchSolid Earth, 114, B04411. 
Ingebritsen SE, Gleeson T (2015) Introduction to the special issue on crustal permeability. Geofluids, 15, 1-10.

Ingebritsen SE, Manning CE (2010) Permeability of the continental crust: dynamic variations inferred from seismicity and metamorphism. Geofluids, 10, 193-205.

Ingebritsen SE, Sanford S, Neuzil C (2006) Groundwater in GeologicProcesses, 2nd edn. Cambridge University Press, New York, pp. 536.

Ingebritsen SE, Geiger S, Hurwitz S, Driesner T (2010) Numerical simulation of magmatic hydrothermal systems. Reviews of Geophysics, 48, RG1002.

Izawa E, Urashima Y, Ibaraki K, Suzuki R, Yokoyama T, Kawasaki K, Koga A, Taguchi S (1990) The Hishikari gold deposit - high-grade epithermal veins in quaternary volcanics of Southern Kyushu, Japan. Journal of Geochemical Exploration, 36, 1-56.

Japan Beyond Brittle Project (2014) Japan Beyond Brittle Project. URL: http://jbbp.kankyo.tohoku.ac.jp/JBBP/outline.html.

Joshi A, Appold MS, Nunn JA (2012) Evaluation of solitary waves as a mechanism for oil transport in poroelastic media: a case study of the South Eugene Island field, Gulf of Mexico basin. Marine and Petroleum Geology, 37, 53-69.

Jupp T, Schultz A (2000) A thermodynamic explanation for black smoker temperatures. Nature, 403, 880-3.

Kesler SE (1994) Mineral Resources, Economics and The Environment, p. 391. Macmillan Publishing Co, New York, NY.

Landtwing MR, Pettke T, Halter WE, Heinrich CA, Redmond PB, Einaudi MT, Kunze K (2005) Copper deposition during quartz dissolution by cooling magmatic-hydrothermal fluids: the Bingham porphyry. Earth and Planetary Science Letters, 235, 229-43.

Lecumberri-Sanchez P, Steele-MacInnis M, Weis P, Driesner T, Bodnar RJ (in press) Salt precipitation in magmatic-hydrothermal systems associated with upper crustal plutons. Geology, vol. 43, pp. 1063-1066.

Manning CE, Ingebritsen SE (1999) Permeability of the continental crust: implications of geothermal data and metamorphic systems. Reviews of Geophysics, 37, 127-50.

Matthai SK, Geiger S, Roberts SG, Paluszny A, Belayneh M, Burri A, Mezentsev A, Lu H, Coumou D, Driesner T, Heinrich CA (2007) Numerical simulation of multi-phase fluid flow in structurally complex reservoirs. In: Structurally Complex Reserviors (eds Jolley SJ, Barr D, Walsh JJ, Knipe RJ), vol. 292, pp. 405-29. The Geological Society, London.

Micklethwaite S, Ford A, Witt W, Sheldon HA (2015) The where and how of faults, fluids, and permeability - Insights from fault stepovers, scaling properties, and gold mineralization. Geofluids, 15, 
240-51.

Miller SA, Nur A (2000) Permeability as a toggle switch in fluid-controlled crustal processes. Earth and Planetary Science Letters, 183, 133-46.

Miller SA, Collettini C, Chiaraluce L, Cocco M, Barchi M, Kaus BJP (2004) Aftershocks driven by a high-pressure $\mathrm{CO}_{2}$ source at depth. Nature, 427, 724-7.

Muntean JL, Einaudi MT (2000) Porphyry gold deposits of the Refugio district, Maricunga belt, northern Chile. Economic Geology, 95, 1445-72.

Norton D, Knight J (1977) Transport phenomena in hydrothermal systems: cooling plutons. American Journal of Science, 277, 937-81.

Pokrovski GS, Borisova AY, Harrichoury JC (2008) The effect of sulfur on vapor-liquid fractionation of metals in hydrothermal systems. Earth and Planetary Science Letters, 266, 345-62.

Preisig G, Eberhardt E, Gischig V, Roche V, van der Baan M, Valley B, Kaiser P, Duff D, Lowther R (2015) Development of connected rock mass permeability through hydraulic fracture propagation and shearing accompanying fluid injection. Geofluids, 15, 321-37.

von Quadt A, Erni M, Martinek K, Moll M, Peytcheva I, Heinrich CA (2011) Zircon crystallization and the lifetimes of ore-forming magmatic-hydrothermal systems. Geology, 39, 731-4.

Redmond PB, Einaudi MT, Inan EE, Landtwing MR, Heinrich CA (2004) Copper deposition by fluid cooling in intrusion-centered systems: new insights from the Bingham porphyry ore deposit, Utah. Geology, 32, 217-20.

Revil A, Cathles LM (2002) Fluid transport by solitary waves along growing faults - A field example from the South Eugene Island Basin, Gulf of Mexico. Earth and Planetary Science Letters, 202, 321-35.

Rice JR (1992) Fault stress states, pore pressure distributions, and the weakness of the San Andreas Fault. In: Fault Mechanics and TransportPropertiesofRocks (ed. Evans B, Wong TF), vol. 51, pp. 475-503. Academic, New York, NY.

Richards JP (2013) Giant ore deposits formed by optimal alignments and combinations of geological processes. Nature Geoscience, 6, 911-6.

Rojstaczer SA, Ingebritsen SE, Hayba DO (2008) Permeability of continental crust influenced by internal and external forcing. Geofluids, 8, 128-39.

Saffer D (2015) The permeability of active subduction plate boundary faults. Geofluids, 15, 193215.

Scott S, Driesner T, Weis P (2015) Geologic controls on supercritical geothermal

resources above magmatic intrusions. Nature Communications, 6, 7837, doi: 10.1038/ncomms8837. 
Shinohara H (2008) Excess degassing from volcanoes and its role on eruptive and intrusive activity. Reviews of Geophysics, 46, RG4005.

Sibson RH (1987) Earthquake rupturing as a mineralizing agent in hydrothermal systems. Geology, 15, 701-4.

Sibson RH, Robert F, Poulsen KH (1988) High-angle reverse faults, fluid-pressure cycling, and mesothermal gold-quartz deposits. Geology, 16, 551-5.

Sillitoe RH (2010) Porphyry Copper Systems. Economic Geology, 105, 3-41.

Walder J, Nur A (1984) Porosity reduction and crustal pore pressure development. Journal of Geophysical Research, 89, 1539-48.

Weis P (2014) The physical hydrology of ore-forming magmatic - hydrothermal systems. Society of Economic Geologists, Special Publication, 18, 59-75.

Weis P, Driesner T (2013) The interplay of non-static permeability and fluid flow as a prerequisite for supercritical geothermal resources. Energy Procedia, 40, 102-6.

Weis P, Driesner T, Heinrich CA (2012) Porphyry-copper ore shells form at stable pressuretemperature fronts within dynamic fluid plumes. Science, 338, 1613-6.

Weis P, Driesner T, Coumou D, Geiger S (2014) Hydrothermal, multi-phase convection of $\mathrm{H}_{2} \mathrm{O}$ $\mathrm{NaCl}$ fluids from Ambient to magmatic temperatures: a new numerical scheme and benchmarks for code comparison. Geofluids, 14, 347-71.

Wilkinson JJ (2013) Triggers for the formation of porphyry ore deposits in magmatic arcs. Nature Geoscience, 6, 917-25.

Zoback MD, Harjes HP (1997) Injection-induced earthquakes and crustal stress at $9 \mathrm{~km}$ depth at the KTB deep drilling site, Germany. Journal of Geophysical Research-Solid Earth, 102, 18477-91.

Zoback MD, Townend J, Grollimund B (2002) Steady-state failure equilibrium and deformation of intraplate lithosphere. International Geology Review, 44, 383-401. 